\title{
Geometrical characterization of stall cells on rectangular wings
}

\author{
Marinos Manolesos ${ }^{1}$, Spyros G. Voutsinas ${ }^{1}$ \\ ${ }^{1}$ Laboratory of Aerodynamics, National Technical University of Athens, 9 Heroon Polytechneiou str., \\ 15780 Athens, Greece. E-mail: marinos @fluid.mech.ntua.gr. \\ Tel: +30 6932 401959, Fax: +30 2107721057
}

\begin{abstract}
The onset of Stall Cells (SCs) is experimentally investigated on a flat-top loaded $18 \%$ thick airfoil optimized for use on wind turbine blades, exhibiting trailing edge separation. SCs are dynamic coherent vortical structures that appear on wings under separated flow conditions. Although SCs have been known for long, neither are their characteristics completely documented, nor their generating mechanisms fully understood. The present investigation aims at providing additional information on the geometric characteristics in terms of width, length and occupied area. The relevant data are presented as functions of Reynolds (Re) number, angle of attack and aspect ratio (AR) of the model. In the tests reported the dynamic character of SCs is suppressed by imposing a localized flow disturbance. For the specific airfoil and for the Re and AR range tested it is found that: the angle of attack at which SCs are initially formed decreases linearly with Re number and independently of the AR; unlike two-dimensional separation their chordwise length increases with Re; the SC area relative to the wing planform area (defined as the relative $\mathrm{SC}$ area) grows asymptotically with angle of attack and Re number reaching an upper bound which is independent of the AR; at intermediate angles of attack the SC relative area is higher for the lower AR wing; for a fixed increment in Re number, the growth of the SC relative area is independent of the initial Re number; at lower angles of attack the actual SC area is independent of the wing span.
\end{abstract}

\section{Keywords}

Stall Cells, Tuft Flow Visualization, Three Dimensional Separation, Wing Aerodynamics

\section{Introduction}

Wind turbine blades are currently designed on the basis of steady 2D (sectional) polars that are obtained by combining steady CFD calculations or panel codes that include strong viscous-inviscid interaction coupling methods and wind tunnel tests on rectangular wing models in a comprehensive way (e.g. [1,2]). Therefore the confidence in the design strongly depends on the quality of the sectional polars. 
Aiming at smooth lift development with respect to the effective angle of attack and adequate thickness for load resistance, wind turbine blades are often designed on the basis of profiles with flat-top pressure distributions. Airfoils of this type exhibit TE separation which renders them prone to the formation of the so called "stall cells" as concluded in the extensive airfoil profile investigation of Broeren and Bragg [3]. For airfoil stall classification see [4] and [5] .

Stall cells (SC) are three dimensional coherent structures that consist of two counter rotating vortices. A comprehensive study [6] reports that SCs have been observed in the separated flow region behind flat plates, circular cylinders, shock induced separation and finite wings. Even earlier [7] questions had been raised on the validity of two dimensional wing tests when SCs were formed. Up until today though, the SCs characteristics are not completely documented, neither have their generating mechanisms been fully understood. It is towards this aim that the present investigation was conducted, in connection to wind turbine blade design.

The investigation refers to an $18 \%$ thick airfoil profile designed at National Technical University of Athens (NTUA), Mourikis et al [8], and includes wind tunnel testing and CFD simulations. The specific profile resulted from shape optimization for use on variable pitch and variable speed multi MW wind turbine rotors based on evolution algorithms and use of XFOIL, Drela [9], as flow solver. It belongs to the flat-top type experiencing TE separation leading to a gradual built-up of the lift and smooth post stall behaviour. The present paper refers to the geometrical characterization of SCs based on flow visualization using tufts and starts with a review of previous works on SCs. Then the experimental approach is described followed by results and their discussion. The main conclusions are summarized in the final section whereas detailed photos from the experiments are given in the Appendix. More photos and videos are available in [10] while [11] reports on the pressure data and the CFD simulations.

\section{Survey on previous works}

Table 1 lists some of the most significant experimental studies that detected threedimensional cellular patterns of separated flow in nominally two-dimensional configurations. There is a wide variety of airfoil shapes, airfoil thickness values, aspect ratio values (ARs) and operating Reynolds (Re) numbers.

Most researchers have found that SCs are dynamic structures. Yon and Katz [12] using tufts, found that at a Reynolds (Re) number of $0.6 \times 10^{6}$ (turbulence intensity $1 \%)$ SCs moved in the spanwise direction. Earlier, but at higher Re numbers $(\operatorname{Re}>$ $\left.0.75 \times 10^{6}\right)$ Gregory et al. [7, 10] reported "intermittent flicking between the un-stalled and the stalled patterns" and "arbitrary change in the number of SCs formed". Zarutskaya and Arieli [14] also found lateral irregular motion of the SCs on their NACA 0012 model at a chord Re number of $0.39 \times 10^{6}$. On the contrary in their tests at lower Re $\left(0.3 \times 10^{6}\right)$, Broeren and Bragg [3] did not report any SC movement as such 
but reported non-symmetrical separation in the spanwise direction. Worth noting is that in Broeren and Bragg's experiments the turbulence intensity was less than $0.1 \%$. No such information is given in the other tests.

Theoretical results suggest that SCs could be the result of spanwise flow instability. At low Re number $(\mathrm{Re}=200)$ and for an airfoil in deep (laminar) stall, Rodríguez and Theofilis [15] via a BiGlobal stability analysis [16] attributed the generation of SCs to the amplification of spanwise instability. Recently, Elimelech et al. [17] showed on the basis of measurements at low Re numbers that the amplification of a twodimensional perturbation cannot justify the formation of structures of such a large scale as the SCs and that SCs could be explained as result of a spanwise 3D perturbation.

In deep stall, the separation bubble is formed by two intense shear layers, one originating from the TE and the other from the separation point releasing vorticity of opposite sign into the flow. Under these conditions, a spanwise perturbation can trigger the development of a Crow like instability [18], as Weihs and Katz [19] first suggested.

Also at low Re, the computational study of Taira and Colonius [20] for the flat plate case, showed that a small wing of $A R=1$ does not give $S C$, unlike wings of higher AR ( $A R=2-4)$ indicating that a minimum span (or equivalently a lower bound in wave length) is needed. Beyond that level, multiple SCs can be formed. In various studies [20-22] the number of SCs was found to increase as the span of the model increased.

With regard to the effect of the angle of attack, $\alpha$, Winkelman and Barlow [21] report that by increasing $\alpha$ (at $\operatorname{Re}<0.4 \times 10^{6}$ ) fewer, but wider cells were created. Also, Schewe [22] in his wide Re number range study found that for a specific angle of attack the SC structures would appear only after a certain Re number.

Multiple reports state that the formation of stall cells is not caused by a tip effect. Gregory et al. [7] report that for a wall to wall model suction at the tip region did not prevent the formation of SCs. Winkelmann and Barlow [21] found that for a Clark Y $14 \%$ thick airfoil the number of SCs increased when the AR increased from 3 to 12. Yon and Katz [12] came to the same conclusion for a NACA 0015 airfoil and ARs values from 2 to 6 , by increasing the model span and therefore the AR for a fixed Re number. The latter authors also suggest that the number of SCs on a wing equipped with tip plates is greater than that on a wing with free tips. Finally Schewe [22] found that SCs are not restricted to the wall region when the aspect ratio of a $27 \%$ thick airfoil was raised from 4 to 6 and suggested that the width of a single SC remains intact as the AR grows. So, the conclusion from the above references is that no tip condition (wall to wall with or without suction, free tips or endplates) can prevent the formation of SCs. 
As regards boundary layer tripping, in an early report by Moss and Murdin [23], tripping on the suction side of the airfoil lead to the creation of stall cells at lower angle of attack. To the authors' knowledge no other report of a SC on a tripped wing has been published.

\section{Experimental approach}

All tests were carried out at the NTUA wind tunnel. The tunnel is of the closed-return type and the turbulence intensity in the test section is $0.2 \%$. The wing model had a chord of $0.6 \mathrm{~m}$ and spanned the test section vertically, a distance of $1.4 \mathrm{~m}$. The width of the test section was $1.8 \mathrm{~m}$, so that the vertical orientation of the model ensures minimum blockage. The solid blockage of the model was $6.9 \%$ of the tunnel section at 12 degrees angle of attack and reached a maximum of $9.2 \%$ at the highest angle, 16 degrees, still below $10 \%$, see [24].

In order to minimize the effect of the wind tunnel boundary layer, side fences were added (Figure 1). By moving the fences along the wing span the aspect ratio of the model could vary, keeping the Re number constant. Figure 1 also shows a side view of the test set up. Tests were carried out at three different Re numbers, $0.5 \times 10^{6}$, $1.0 \times 10^{6}$ and $1.5 \times 10^{6}$, and two different spans and therefore aspect ratios, namely $\mathrm{AR}=1.5$ and 2.0. In the following when trends do not change with Re number or AR, results are shown for only one Re number or AR in order to keep the length of the paper reasonable.

For the pressure measurements a total of 62 pressure taps was used. They were distributed from LE to $88.8 \%$ of the chord at the centre of the wing span (details on pressure measurements can be found in [11]).

For the tuft visualization experiments, No 60 sewing threads were fitted over the suction side of the model in spanwise rows with $4 \mathrm{~cm}$ spacing between them. The chordwise position of the tufts is shown in Figure 2 (left). Every single tuft was individually taped on the model surface in order to minimize their interference to the boundary layer. At each setting ( $\mathrm{Re}, \mathrm{AR}, \alpha$, zigzag tape) a video of at least $30 \mathrm{sec}$ was filmed and analyzed according to the following rule: a tuft would be considered "belonging to a SC" if it would deviate from the chordwise direction most of the time during a run. Based on the number of tufts belonging to a SC the following geometrical metrics were introduced, all defined in Figure 3:

a) The SC width as $\%$ of the span (SC width $=\mathrm{z} / \mathrm{S}$ )

b) The most upstream $\mathrm{x} / \mathrm{c}$ location of the $\mathrm{SC}$ boundary (earliest separation point)

c) The SC area as \% of the wing planform area

$$
S C_{\text {relative area }}=\frac{\mathrm{SC}_{\text {actual area }}}{\text { Wing planform area }}
$$


These metrics were chosen to examine the SC size and shape which clearly affects the wing performance. For example it is common practice for wind tunnel wing models to have pressure taps only at a single spanwise location, usually at the mid span. In the case of a single SC the earliest separation point would crucially affect the measured pressure distribution.

For each of the spanwise series of tufts that a SC would occupy, the uncertainty would be $+/-2$ tufts, i.e. one tuft on each end of the tuft series. Therefore the uncertainty in the measurement of the SC width is $+/-6.7 \%$ and $+/-9.1 \%$ for AR 2.0 and 1.5, respectively. Similarly, the chordwise uncertainty for the SC boundary line is approximately $+/-10 \%$. Finally the uncertainty for the SC area ranged from $+/-1.6 \%$ (smallest SC) to $+/-3.5 \%$ (largest $\mathrm{SC}$ ) of the wing area for the $\mathrm{AR}=2.0$ case and from $+/-1.2 \%$ to $+/-4.7 \%$ for the $\mathrm{AR}=1.5$ case. The error bars in the following graphs are drawn based on the maximum values.
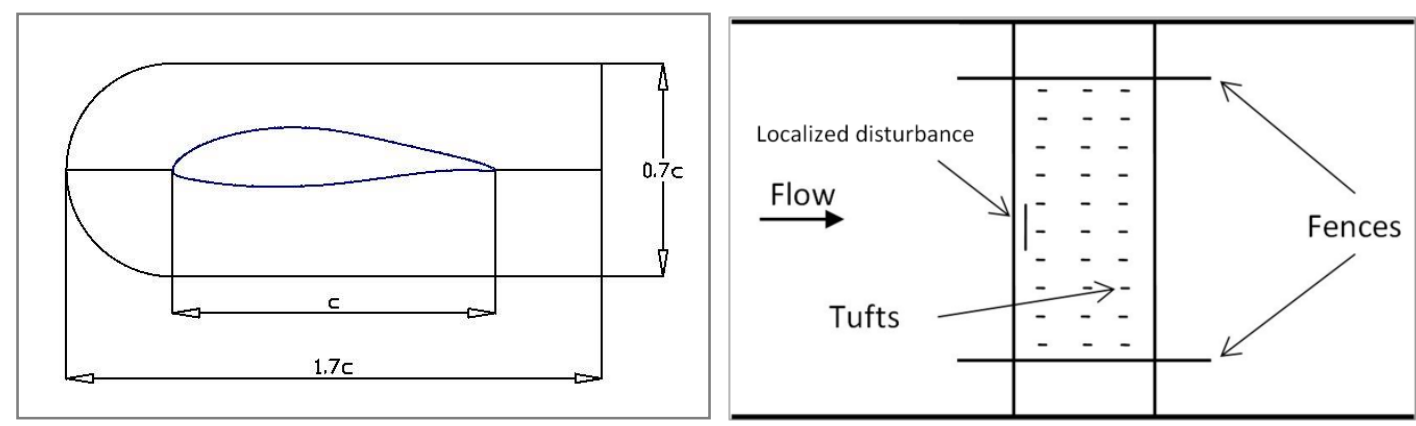

Figure 1: (left) Fences shape and dimensions (1.7c long, $0.7 \mathrm{c}$ wide). (right) Side view of the test set up
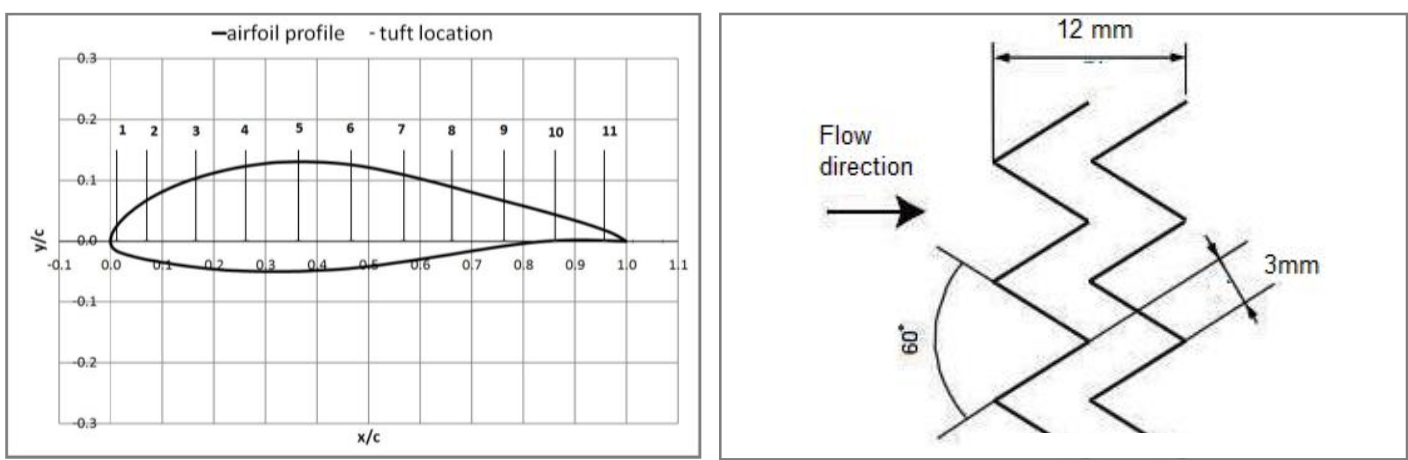

Figure 2: (left) The airfoil profile and chordwise location of tufts. (right) The zigzag tape dimensions 


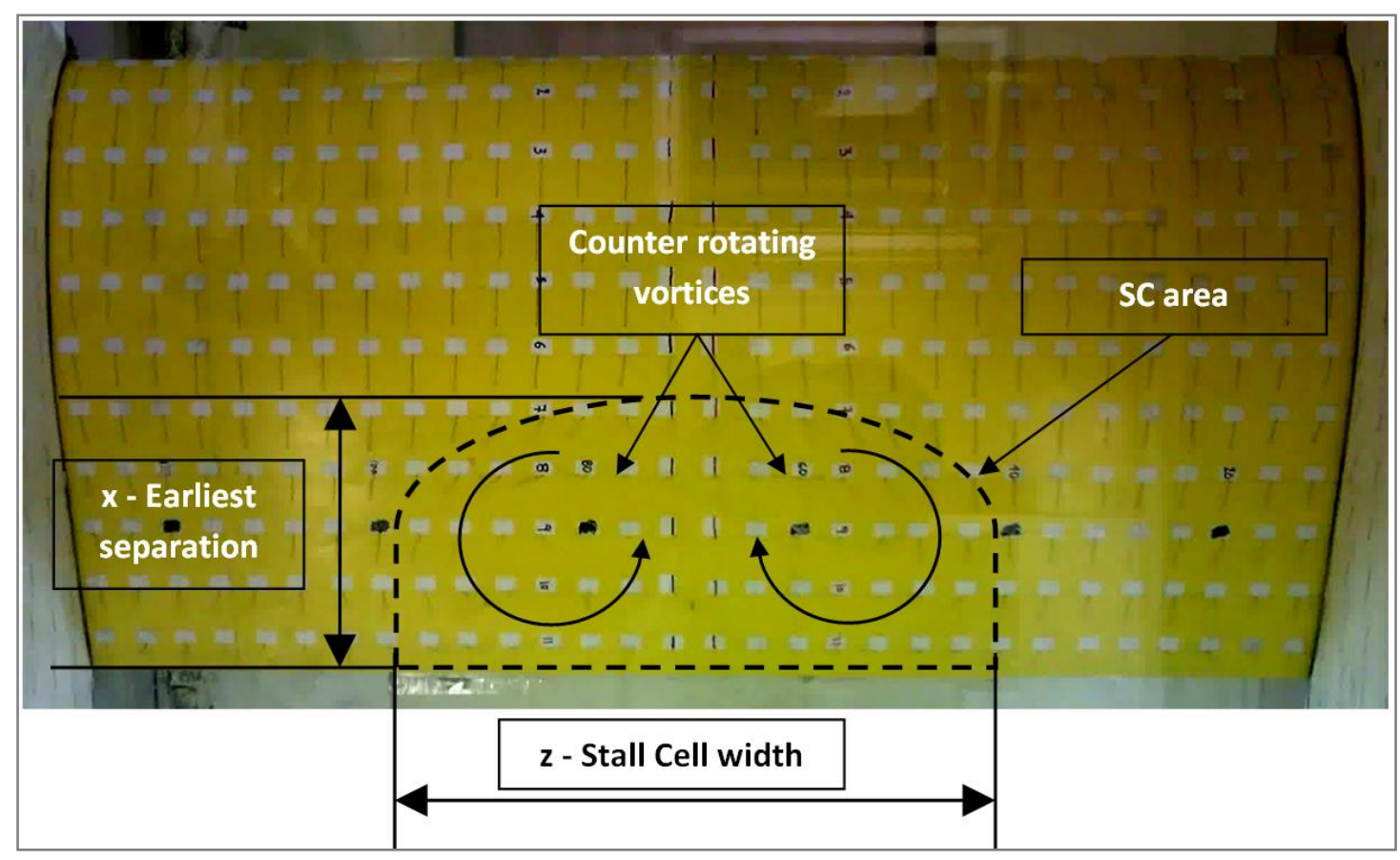

Figure 3: Schematic view of a $\mathrm{SC}$ for $\mathrm{AR}=\mathbf{2 . 0}, \mathrm{Re}=1.0$ million, $\mathrm{a}=\mathbf{8 . 0}$ degrees, with local disturbance at the wing span centre. The direction of the flow is from top to bottom.

In order to check whether the tufts correctly follow the flow even at the lowest Re number, the tuft data were compared with pressure data in Figure 4. The earliest separation point at the wing mid-plan for the AR 2.0, Re number $0.5 \times 10^{6}$ case with zigzag (ZZ) tape is plotted against angle of attack for both the tuft and the pressure data. The agreement is very good and therefore the tuft data are trustworthy even at the lowest free stream velocity.

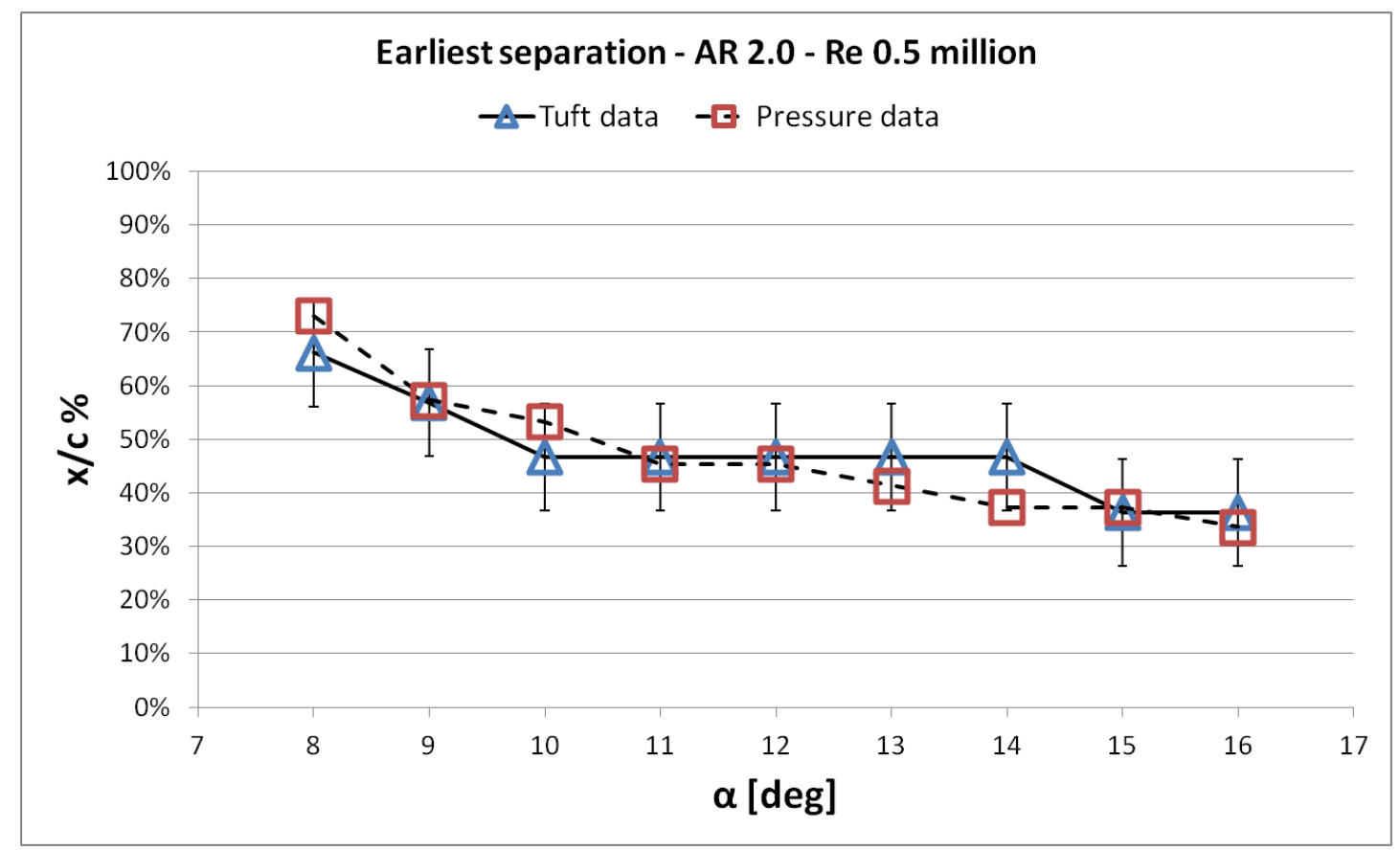

Figure 4: Earliest point of separation as found by tuft and pressure data for Re 0.5 million, $A R=2.0$, with a localised disturbance using a $\mathrm{ZZ}$ tape. The two sets agree well and so trustworthy conclusions can be drawn from the tuft data. 
The first series of tests were conducted without any extra flow perturbation apart from what the tufts themselves induce, aiming at exploring the possible dynamic behaviour of SCs at higher Re numbers as compared to the findings of previous works $[7,9]$.

Patterns with one, one and a half or two SCs were observed indicating the existence of multiple modes. On occasions even a "half SC" would form at the wing tips, i.e. only one vortex structure next to the fence forming a "full SC" together with its mirror vortex with respect to the fence wall. Similar oil flow visualization results have been reported by Velte et al. [26] $\left(\operatorname{Re} 2.410^{6}\right)$ and earlier by Gregory et al. [7] (Re 3.14 $\left.10^{6}\right)$

In certain cases, the pattern switched from one state to another, in others a single SC would move in the spanwise direction while in yet others there were one or several SCs that appeared and disappeared in a seemingly random manner. In this first series of tests longer videos were filmed (even longer than $60 \mathrm{sec}$ ) to allow for the different states of the flow to be documented, however, clear correlation with any of the basic flow parameters (Re number or angle of attack) was not concluded.

Next a zigzag (ZZ) tape was fitted all along the span at the LE of the model that did not cancel the dynamic character of the SCs suggesting that the dynamic nature of SCs is not linked to transition.

Assuming, in accordance to the theoretical analysis by Rodríguez and Theofilis [15], that SCs result from large enough self-excited and self-sustained spanwise perturbations, it was decided to force the flow to select one such mode by introducing a spanwise disturbance and therefore render the further investigation possible. A $0.4 \mathrm{~mm}$ thick zigzag tape with $60^{\circ}$ angle, see Figure 2 (right) was added at mid-span covering $10 \%$ of the span. The tape was placed at $\mathrm{x}=0.02 \mathrm{c}$ so that it would always be at or prior to natural transition. The specific position is the natural transition point that XFOIL [9] predicts for the highest Re number $\left(1.5 \times 10^{6}\right)$ and angle of attack (16deg) tested. No ZZ tape was added on the pressure side. Of course, a ZZ tape of sufficient height would also locally trip the flow, apart from introducing a localized disturbance. However this was not the purpose in the present case. It was decided to use an oversized ZZ tape even for the lowest Re number $\left(0.5 \times 10^{6}\right)$ so that the trip tape would be oversized throughout the range of Re numbers considered.

In order to only trip the boundary layer at this chord position $(0.02 \mathrm{c})$ for the lowest $\mathrm{Re}$ number in this test $\left(0.5 \times 10^{6}\right)$, a grit roughness height of about $0.88 \mathrm{~mm}$ would be sufficient, as calculated by the method of Braslow and Knox [27]. ZZ tapes, however, are more effective in tripping the flow than grit roughness as Timmer and Van Rooij [2] suggest and according to their approach a $\mathrm{ZZ}$ tape of $0.29 \mathrm{~mm}$ height would be high enough to trip the flow. For Re number of $1.0 \times 10^{6}$ and $1.5 \times 10^{6}$ the corresponding tape heights are $0.14 \mathrm{~mm}$ and $0.09 \mathrm{~mm}$, respectively. Clearly the effect 
of the specific tape is not entirely the same, given the Re number and angle of attack range; however, in all conditions considered the $\mathrm{ZZ}$ tape is met by laminar flow and exceeds height requirements for transition and therefore acts as a disturbance.

Indeed the presence of the specific $\mathrm{ZZ}$ tape led to the creation of a fixed single stall cell positioned at the centre of the wing span. In order to examine the effect of the $\mathrm{ZZ}$ tape in comparison with the undisturbed case, the variation of the relative SC area with respect to the angle of attack at $\mathrm{Re}=1.5 \times 10^{6}$ and for $\mathrm{AR}=2$ is shown in Figure 5 with and without the ZZ tape. Except for a limited difference at $\alpha<9^{\circ}$, the overall agreement is found to be very good. The same was observed for the SC earliest separation point and width throughout the Re numbers and AR range. This suggests that the limited span ZZ tape of the specific height causes an earlier formation of a SC (in agreement with Moss and Murdin [23]) and locks in a single stable SC mode without affecting the amount of separated flow on the wing suction surface for $\alpha \geq 9^{\circ}$.

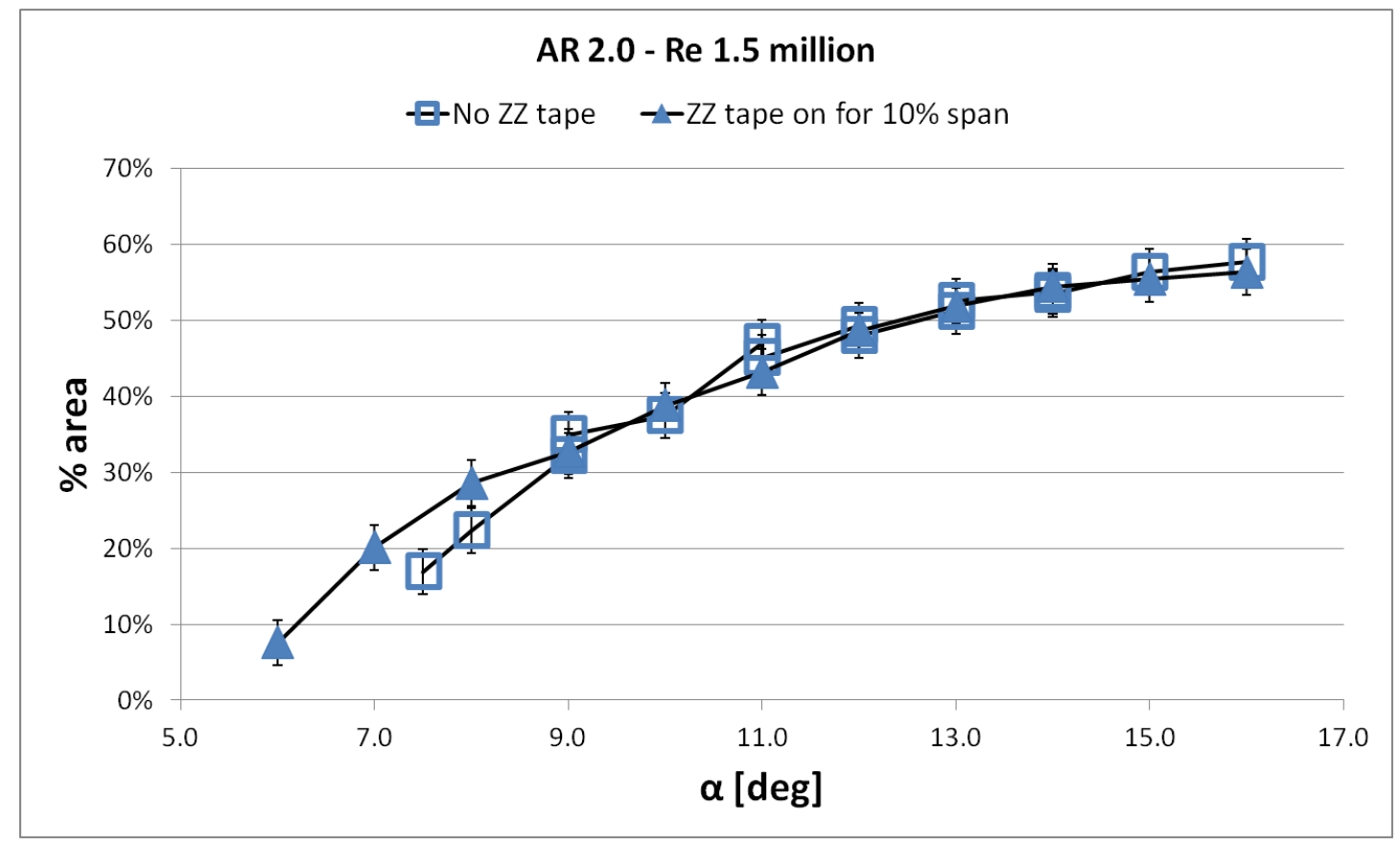

Figure 5: Relative SC area vs. angle of attack, $\mathrm{Re}=1.5$ million, $\mathrm{AR} 2.0$ with and without the $\mathrm{ZZ}$ tape. There is good agreement especially at angles of attack higher than 9 degrees suggesting the addition of the $\mathrm{ZZ}$ tape does not affect the size of the SC. Multiple points on the "no ZZ tape" curve correspond to different flow states (e.g. a single SC alternating with two SCs) for a specific test set up.

\section{Results and discussion}

The vortical structures were identifiable only when the SC was at least 3 tufts long in the chordwise direction and therefore the separation line was at $\mathrm{x} / \mathrm{c}<77 \%$. This is in agreement with Gregory et al. [7] who found that three-dimensionality of the separated flow begins when the chordwise extent of the separated flow region exceeds about $20 \%$ of the chord and shows up as a curved separation line 
In this section the metrics listed below are used in order to geometrically characterize the SC and its behaviour. They are given in terms of Re and angle of attack for two $\mathrm{AR}$ values (or wing spans), namely $\mathrm{AR}=2$ and 1.5 .

- the relative SC width (z/span \%) (Figure 6 and Figure 7),

- the actual SC area (Figure 8),

- the relative SC area (Figure 9 and Figure 10),

- the relative SC growth (Figure 11),

- the maximum chordwise length (Figure 12) and

- the angle at which a SC is first formed (Figure 13)

The relative SC width is increasing with Re number and angle of attack regardless of the AR, as Figure 6 shows for AR 2.0. As this happens the two vortices move toward the wing tips and are elongated in the spanwise direction. For the smaller AR case and for all Re numbers tested the SC reaches the full wing span a lot earlier than for the greater AR, see Figure 7 where the relative SC width is plotted against the angle of attack for Re number $1.5 \times 10^{6}$ and AR 1.5 and 2.0. As an example, the growth of a SC for an increase of $1^{\circ}$ in angle of attack can be seen in Figure 14 and Figure 15 (in the Appendix), where snapshots from the AR 2.0, Re 1.0x10 shown for $\alpha=8.0$ and 9.0 degrees, respectively. Figure 16 shows details from these snapshots where the growth of the SC vortex can be seen more clearly.

Until the SC covers the full span for the low AR case (at $\alpha=9.0$ degrees for $\operatorname{Re}=1.5 \times 10^{6}$ ), the growth of the actual SC area is very similar for both ARs, see Figure 8. This suggests that while sufficiently small, the SC grows unaffected by the proximity of the fences for a wing of fixed chord (and therefore $\mathrm{Re}$ ). Beyond that stage, the SC is forced to grow in the chordwise direction for AR 1.5 whereas it can still expand in both directions for the AR 2.0 case, hence the greater area for $A R=2$ at higher angles of attack. The fact that at an early stage the SC size is not affected by the wing span is shown in Figure 17 and Figure 18 in the Appendix, where snapshots are presented from the $\operatorname{Re} 0.5 \times 10^{6}, 11.0$ degrees, case with $\mathrm{ZZ}$ tape for AR 1.5 and AR 2.0, respectively.

In all cases the relative SC area appears to increase asymptotically with angle of attack as Figure 9 shows for the highest Re number case. The maximum relative SC area depends on the Re number but not on AR, see Figure 10 where the SC area is plotted against angle of attack for $\mathrm{AR}=1.5$ and the three Re numbers tested. Actually after the SC area gets larger than $95 \%$ of its highest value at $\alpha=16^{\circ}$, there is no difference between the two AR cases. This happens for $\alpha>13^{\circ}$ when $\mathrm{Re}=1.5 \times 10^{6}$ and $\mathrm{Re}=1.0 \times 10^{6}$ and for $\alpha>14^{\circ}$ when $\operatorname{Re}=0.5 \times 10^{6}$.

However, the SC relative area is not the same throughout the polar. The initial rate of increase is considerably higher for AR 1.5 than for AR 2.0 leading to higher relative $\mathrm{SC}$ area values for the smaller AR case at intermediate angles of attack. This is explained by the fact that, at low angles of attack the actual SC area is the same for 
the two ARs, whereas the total area is not. For higher angles of attack the rate of increase is gradually reduced for AR 1.5 until the SC reaches the same relative size at the end of the polar in both cases, as mentioned.

The SC relative area increases with Re with a decreasing rate for a given angle of attack (e.g. Figure 10) suggesting that the maximum SC relative area is not expected to grow significantly at higher Re numbers. Snapshots for the AR 2.0, $\alpha=14^{\circ}$ case are given in the Appendix (Figure 19, Figure 20 and Figure 21) for the three Re numbers considered.

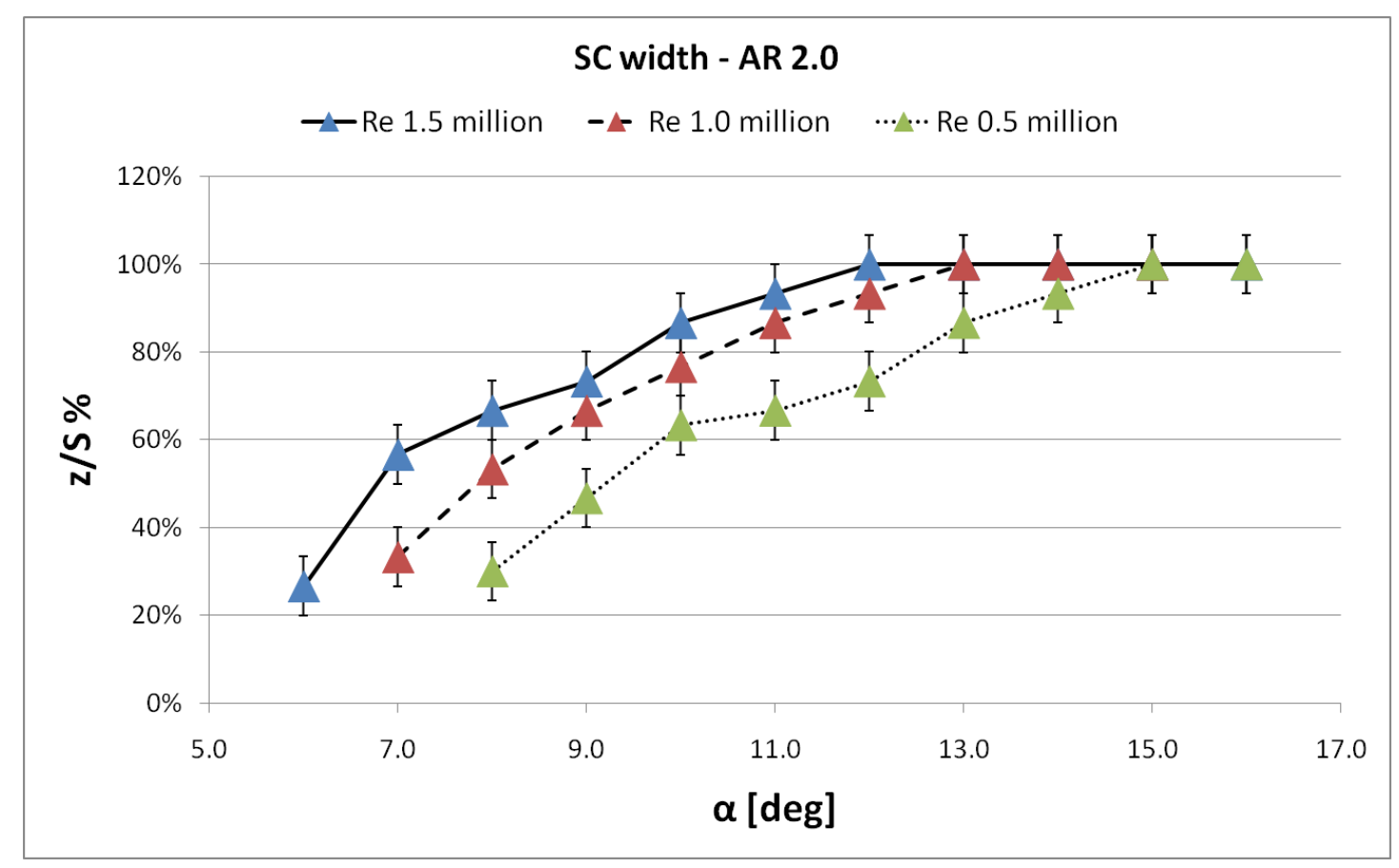

Figure 6: $\mathrm{SC}$ width vs. angle of attack, $\mathrm{AR}=\mathbf{2 . 0}$ for the three Re numbers considered. The SC width increases with Re number and angle of attack. 


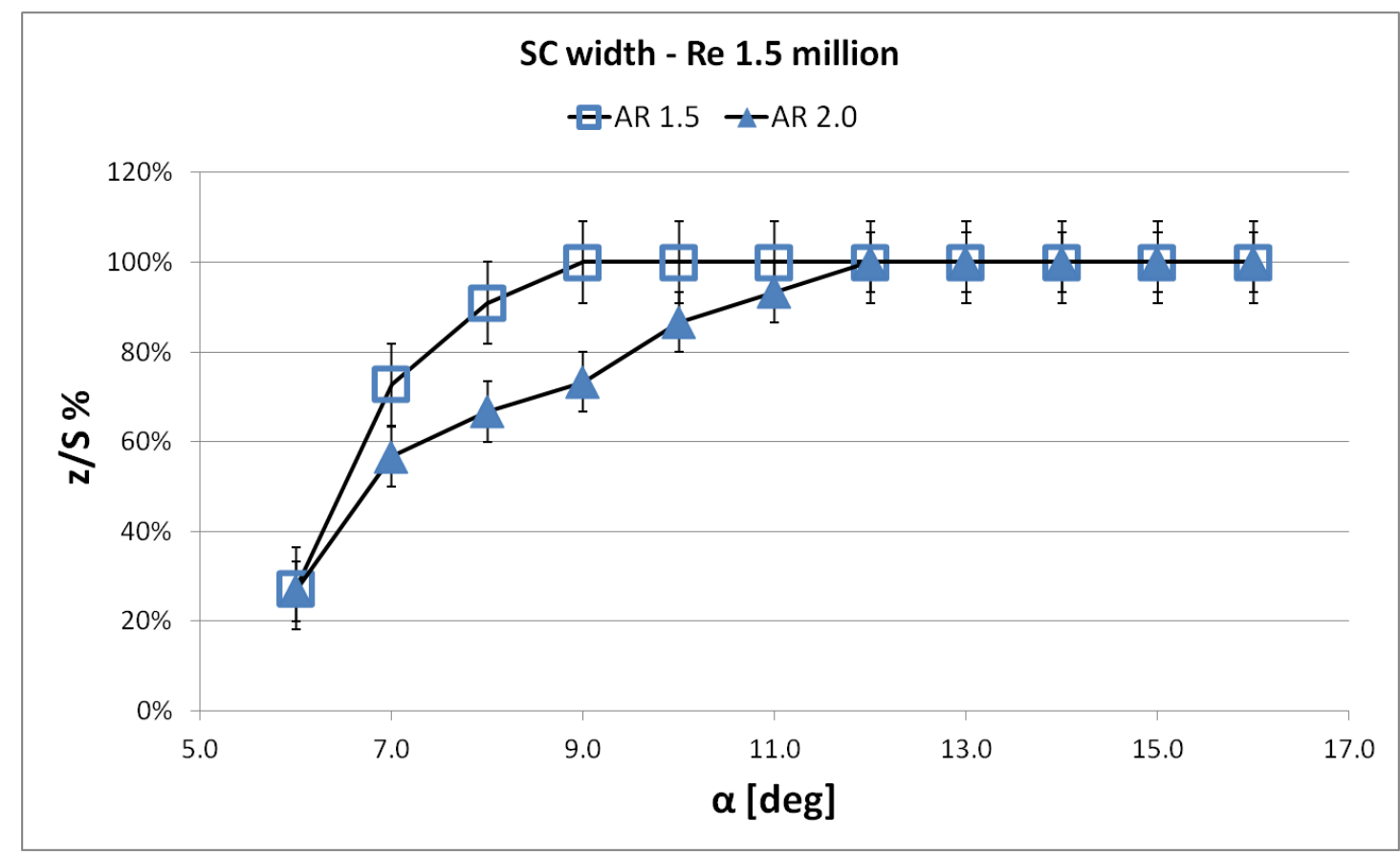

Figure 7: $\mathrm{SC}$ width vs. angle of attack for $\mathrm{AR}=1.5$ and 2 at $\mathrm{Re}=1.5$ million. The $\mathrm{SC}$ reaches the wing full width earlier for the lower AR case.

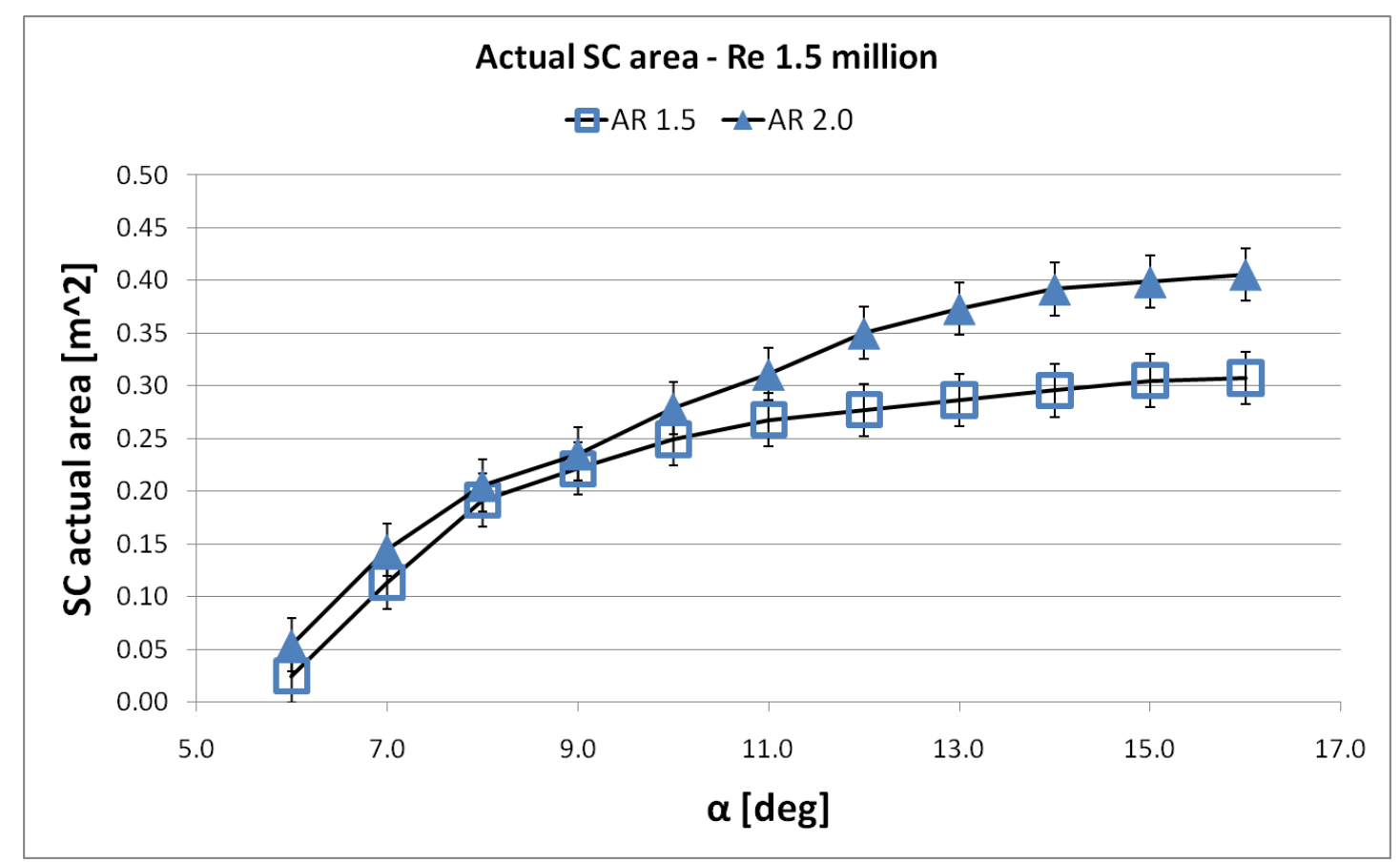

Figure 8: Actual SC area vs. angle of attack, for $\mathrm{AR}=1.5$ and 2 at $\mathrm{Re}=1.5$ million. Until the $\mathrm{SC}$ covers the entire wind span (a<10deg) the SC is unaffected by the end walls. 


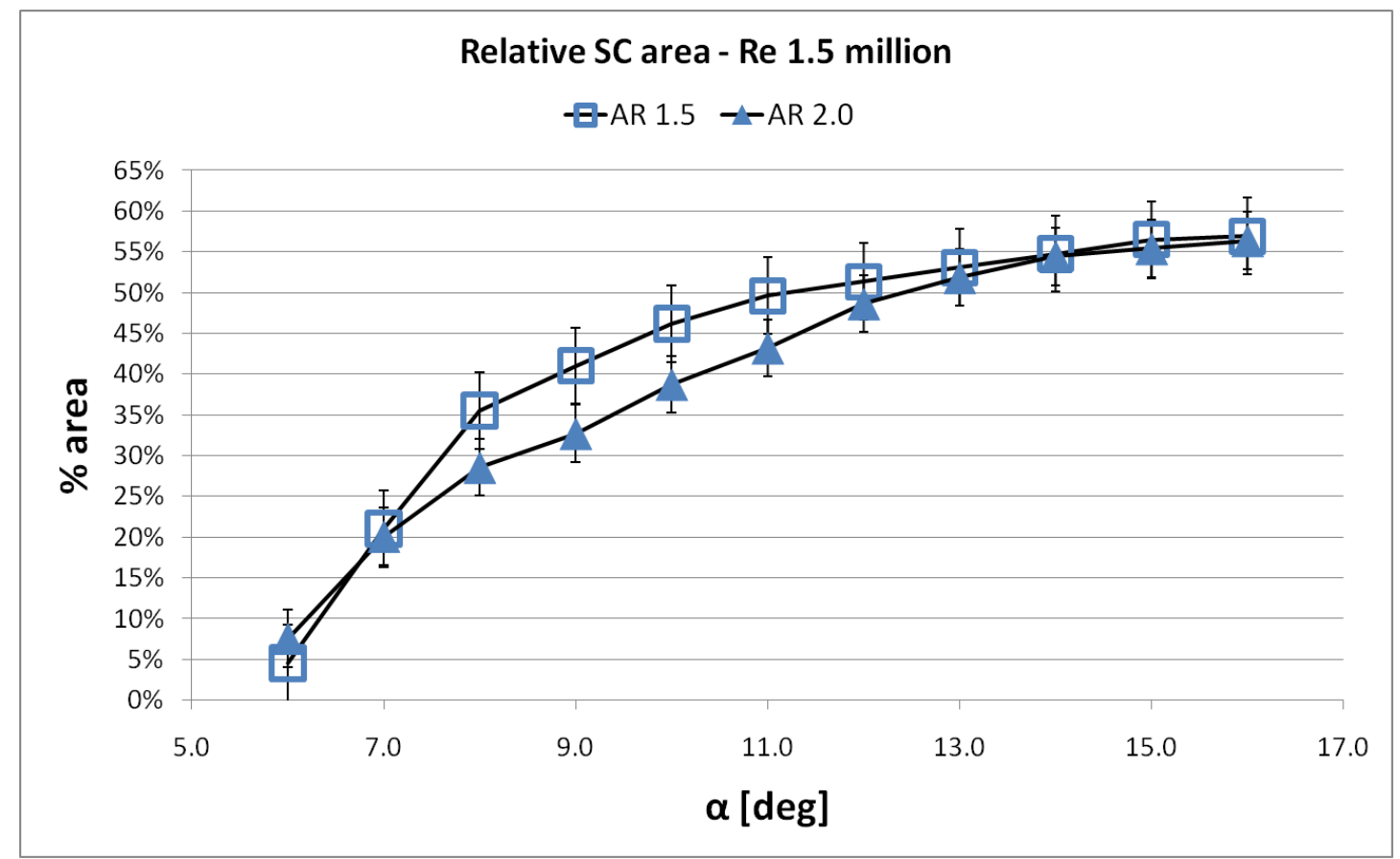

Figure 9: Relative $\mathrm{SC}$ area vs. angle of attack, for $\mathrm{AR}=1.5$ and 2 at $\mathrm{Re}=1.5$ million. The Relative $\mathrm{SC}$ area grows asymptotically with angle of attack to a maximum value that is independent of the AR. At intermediate angles of attack the relative SC area is higher for the lower AR wing.

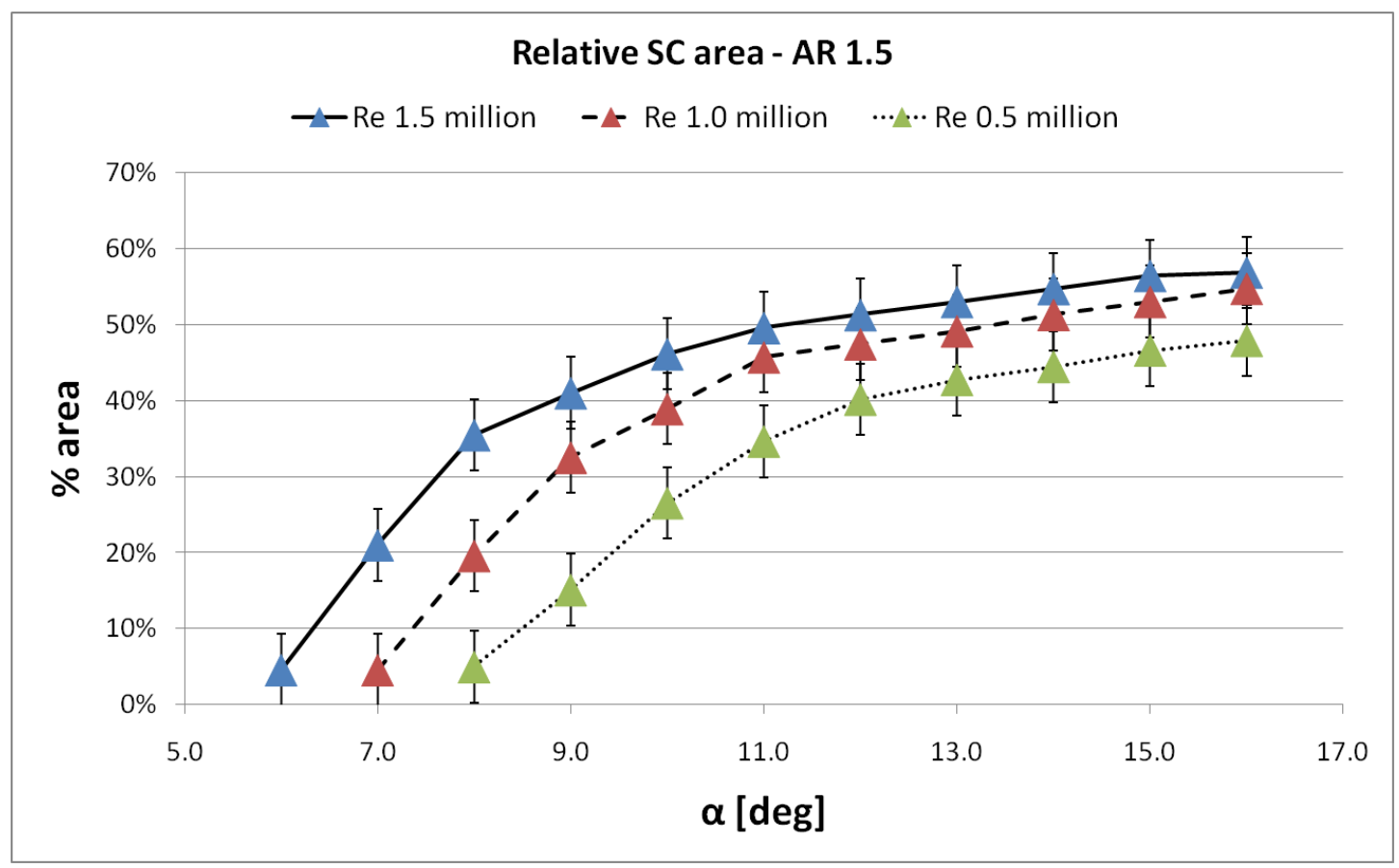

Figure 10: Relative $\mathrm{SC}$ area vs. angle of attack, $\mathrm{AR}=1.5$ for the three Re numbers considered. The relative $\mathrm{SC}$ area maximum value grows with Re number.

In order to better understand the dependence of the $\mathrm{SC}$ relative size growth on $\mathrm{Re}$ number, the relative $\mathrm{SC}$ growth is plotted against the $\mathrm{SC}$ relative area for all the cases tested in Figure 11. The relative $\mathrm{SC}$ growth $\left(S C_{\text {Rel.Growth }}\right)$ is defined as the ratio of the $\mathrm{SC}$ relative area growth for a rise in Re number of $0.5 \times 10^{6}$ over the SC relative area at the final Re number, as shown below. It is interesting to see that the data for the relative SC growth from $\operatorname{Re} 0.5$ to $\operatorname{Re} 1.0 \times 10^{6}$ and from $\operatorname{Re} 1.0$ to $\operatorname{Re} 1.5 \times 10^{6}$ collapse 
on a single curve for each AR case. This suggests that for a specific Re number increase the relevant growth of the SC area is independent of the initial Reynolds number. Also, for relative SC area greater than $40 \%$, i.e. for "big" SCs, the relevant growth seems to be independent of $\mathrm{AR}$ and approaches zero, also suggesting that maximum SC relative area is not expected to grow significantly at higher Re numbers.

$$
S C_{\text {Rel.Growth }}=\frac{\mathrm{SC} \text { relative area } @ \mathrm{Re}_{\mathrm{x}+0.5 \times 10^{6}}-\mathrm{SC}_{\text {relative area } @ \mathrm{Re}_{\mathrm{x}}}}{\mathrm{SC} \text { relative area } @ \mathrm{Re}_{\mathrm{x}+0.5 \mathrm{x} 10^{6}}}
$$

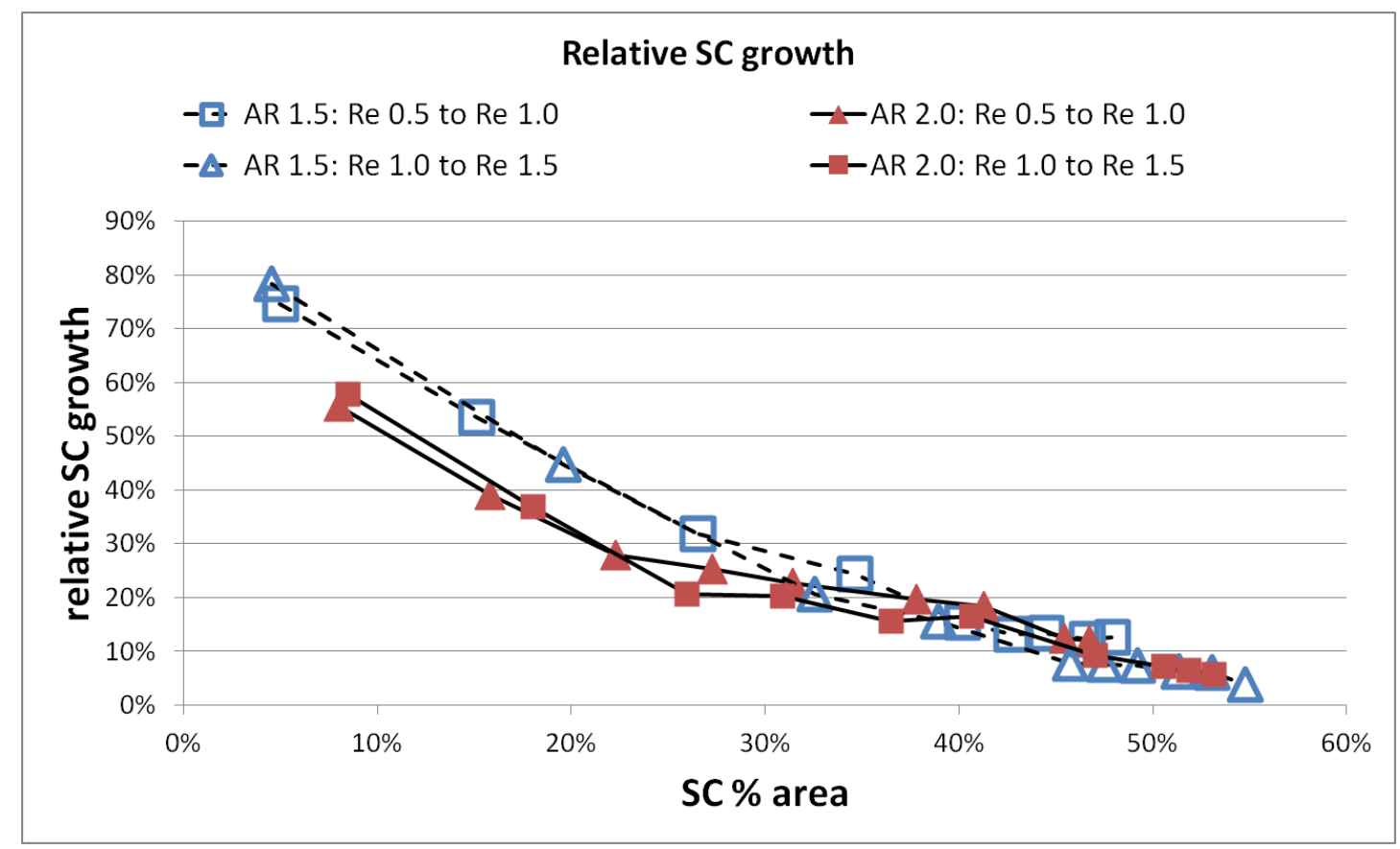

Figure 11: Relative $S C$ growth vs. relative $S C$ area, for the $A R=1.5$ and $A R=2.0$ cases. For a 0.5 million increment in Re number, the SC growth does not depend on the initial Re number.

In all cases the maximum chordwise length of a SC as determined by the earliest separation point, appeared at the centre of the SC between the two counter rotating vortices (e.g. see Figure 3) and no change in behaviour was observed even for the cases without the $\mathrm{ZZ}$ tape. As the angle of attack increases, the earliest separation point quickly moves upstream until it reaches $\mathrm{x} / \mathrm{c}=46.7 \%$ (tuft column $\# 6$ in Figure $2)$; then remains at this level for at least a couple of degrees in all cases, before moving to $\mathrm{x} / \mathrm{c}=36.4 \%$, which is right before the maximum thickness location $(\mathrm{x} / \mathrm{c}=35.1 \%)$. This behaviour is described in Figure 12 where the earliest separation location variation with angle of attack and Re number is given for $A R=2$. Although this behaviour is profile specific, a qualitatively similar behaviour could be expected for other profiles as well, see also [23].

It is observed (Figure 12) that as the Re number increases, the earliest separation point moves upstream contrary to what would be expected in 2D separation. Also unlike 2D separation the angle of attack at which a SC is first formed $\left(\alpha_{\mathrm{SC}}\right)$ decreases with $\mathrm{Re}$ 
number, i.e. raising the Re number does not lead to delay of stall as expected [28], see Figure 13 where $\alpha_{S C}$ is plotted against the Re number for AR 1.5 with and without the ZZ tape. The same behaviour was observed for the AR 2.0 cases, as well. The fact that this behaviour is not altered by the use of $\mathrm{ZZ}$ tape suggests that this is not a local ZZ tape effect.

Both of these "unexpected" phenomena were observed by Yoshida and Noguchi [29] who used a NACA 8313 profile and report onset of separation at a lower angle of attack as Re number increases from $0.5 \times 10^{6}$ to $1.0 \times 10^{6}$ and that for a given angle (e.g. 16 degrees) the separation line moves upstream as Re number increases in the same range. Yoshida and Noguchi attribute this "adverse Re number effect" to the threedimensionality of the separated flow but make no reference to SCs. Still, the threedimensional separation line on the wing could justify the presence of multiple SCs next to one another (e.g. Fig. 11 in [29]).

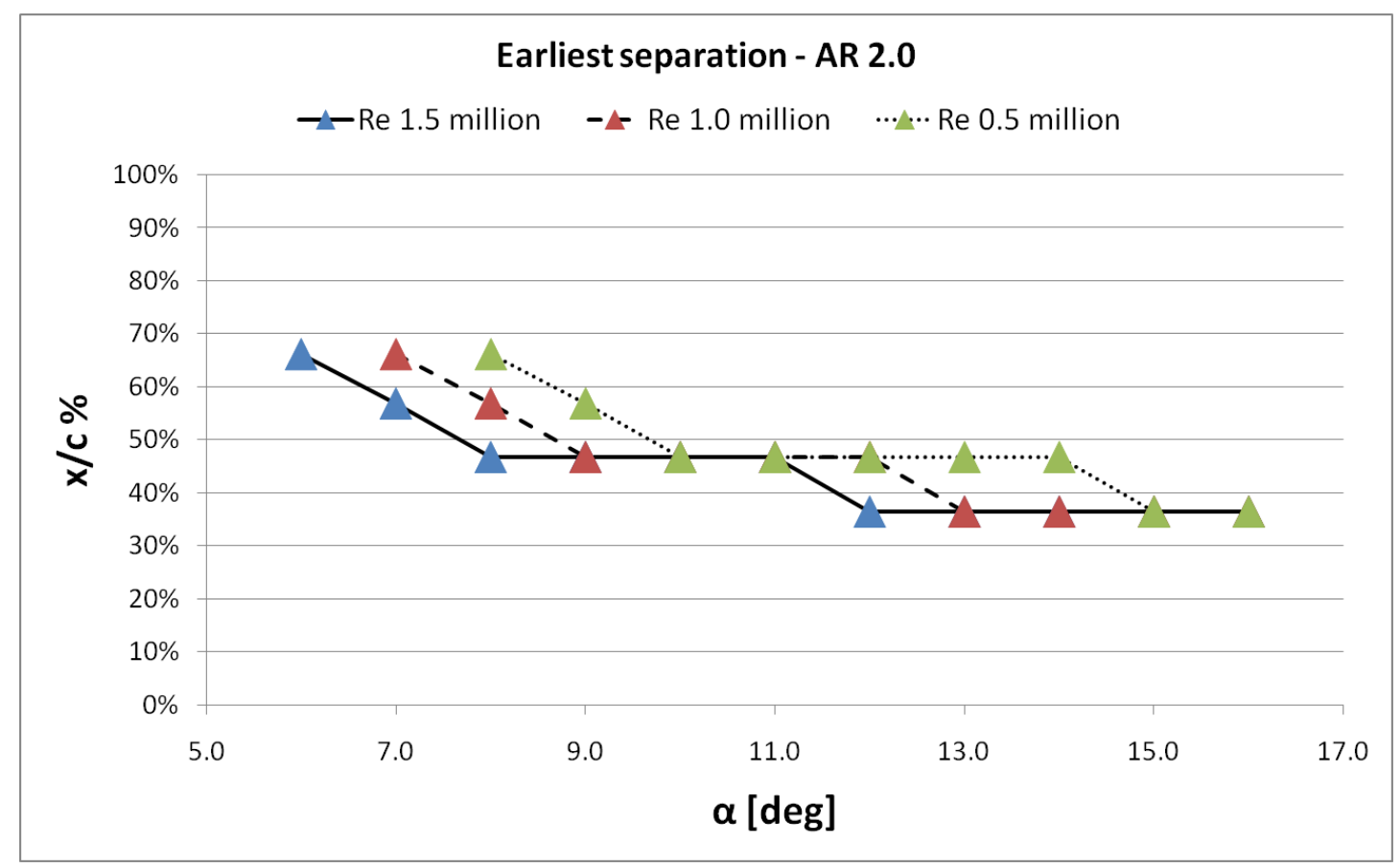

Figure 12: Earliest separation location vs. angle of attack, $A R=2$ at the three Re numbers considered. Unlike in 2D separation, the SC separation line advances forward as the Re number grows, for the range of AR and Re numbers tested indicating an adverse Re effect. 


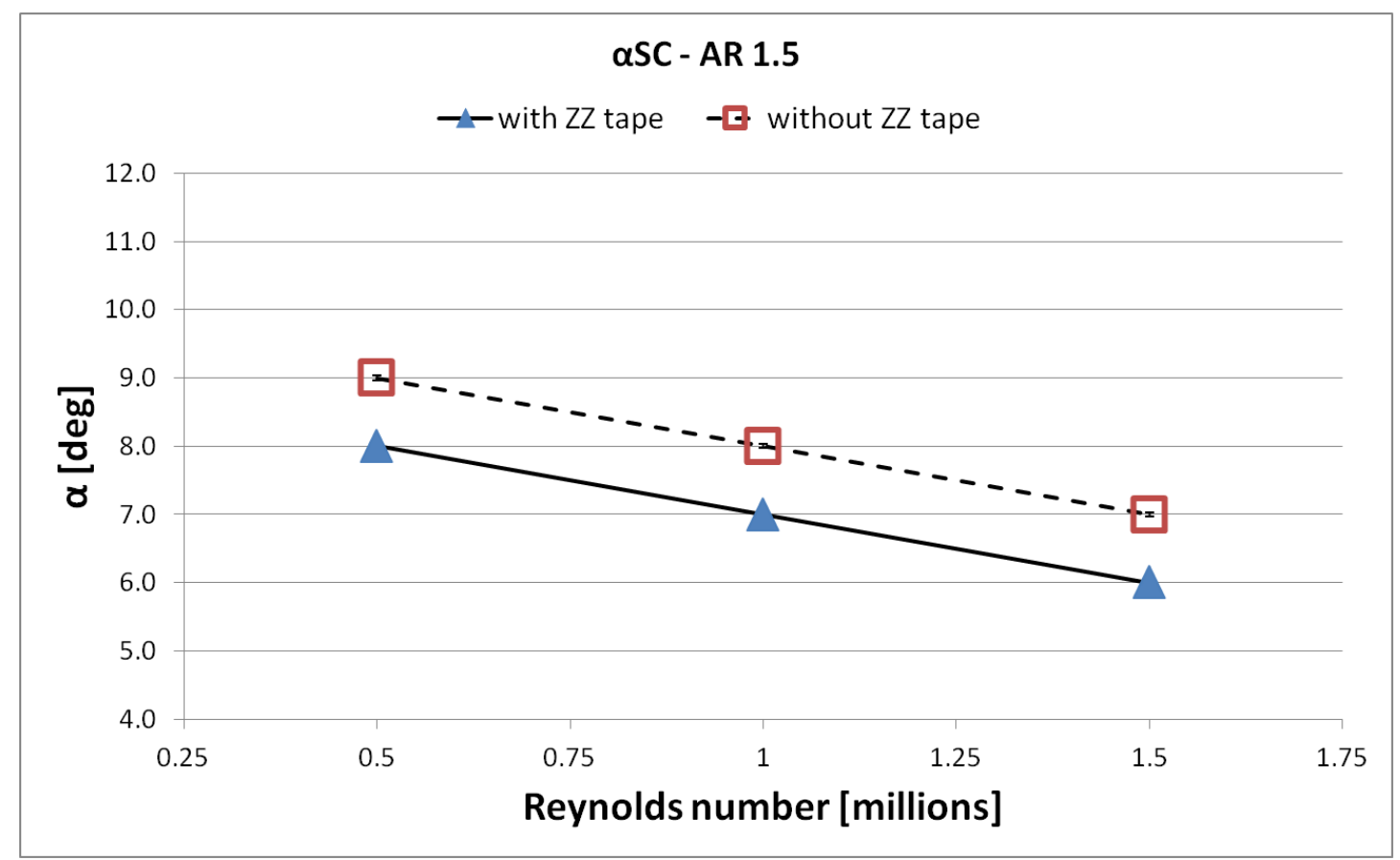

Figure 13: Angle of attack at which a SC is initially formed ( $\left.\alpha_{S C}\right)$ against Re number for AR 1.5 with and without the $\mathrm{ZZ}$ tape. Unlike in 2D separation increasing the Re number leads to earlier onset of stall for the range of $A R$ and $R e$ numbers tested.

\section{Conclusions}

In the present paper the dynamic behaviour of SCs formed on the suction side of a stalled wing (moving and/or spontaneous creation-destruction) reconfirms previous findings. The prerequisite for dynamic SCs to form is that the spanwise flow conditions are uniform (fully tripped or fully un-tripped) which subjects the flow to self-excited perturbations. By applying a local disturbance to the flow (and therefore violating the spanwise uniformity) the flow was forced to create a single stabilized SC. Comparing cases with and without local disturbance indicated that the disturbance does not affect the overall characteristics of the SC size. The effects of Re number and AR (keeping the chord length constant) on this coherent and stable structure were studied experimentally based on tuft visualizations. Pressure measurements and computational data are presented in [11].

A summary of the current study's main findings of is listed below: 
1. The angle at which a SC is first created does not depend on AR and is considered a profile characteristic.

2. As Re increases, the angle at which a SC is first created decreases linearly for the specific profile.

3. Over the range of angles of attack the SC is formed, increasing the Re number results in the upstream advancing of the separation line unlike twodimensional separation. This adverse Re number effect, could be profile specific, but was also noted on a NACA 8318 profile [29].

4. SC relative area grows asymptotically with angle of attack for all the cases tested.

5. Until the SC width entirely covers the available span, the actual SC area is independent of the wing span, over the range of values considered.

6. At high angles of attack, the relative SC area is independent of the AR, over the range of values considered.

7. The relative $\mathrm{SC}$ area is higher for the $\mathrm{AR}=1.5$ case at intermediate angles of attack as compared to that of $\mathrm{AR}=2.0$.

8. For increments of $0.5 \times 10^{6}$ in Reynolds number, the growth of the relative SC area is independent of the Reynolds number.

\section{Acknowledgements}

The authors would like to thank Onassis Foundation who supported this project through the G ZF 032 / 2009-2010 scholarship grant.

\section{Appendix}

The pictures below are snapshots from various set ups, all of them with $\mathrm{ZZ}$ tape. On top of the each picture the SC area is outlined. Even though the snapshots presented here are representative, one should bear in mind that the SC area was measured based on the videos (some are available in [10]) and not on these snapshots. 


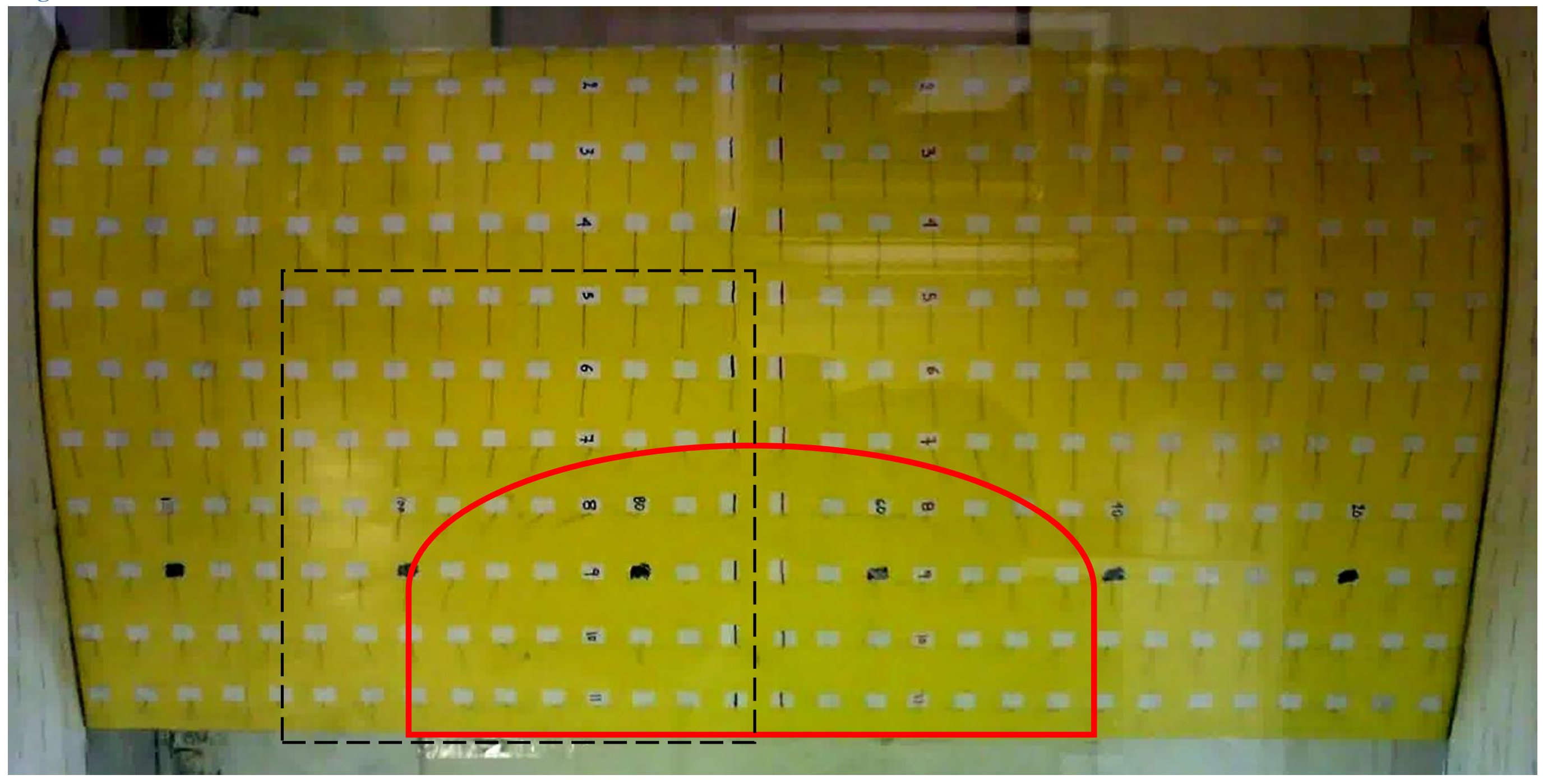

Figure 14: AR 2.0, Re 1.0 million, 8.0 degrees, case with $\mathrm{ZZ}$ tape. Outlined is the area shown in Figure 16 (Left). 


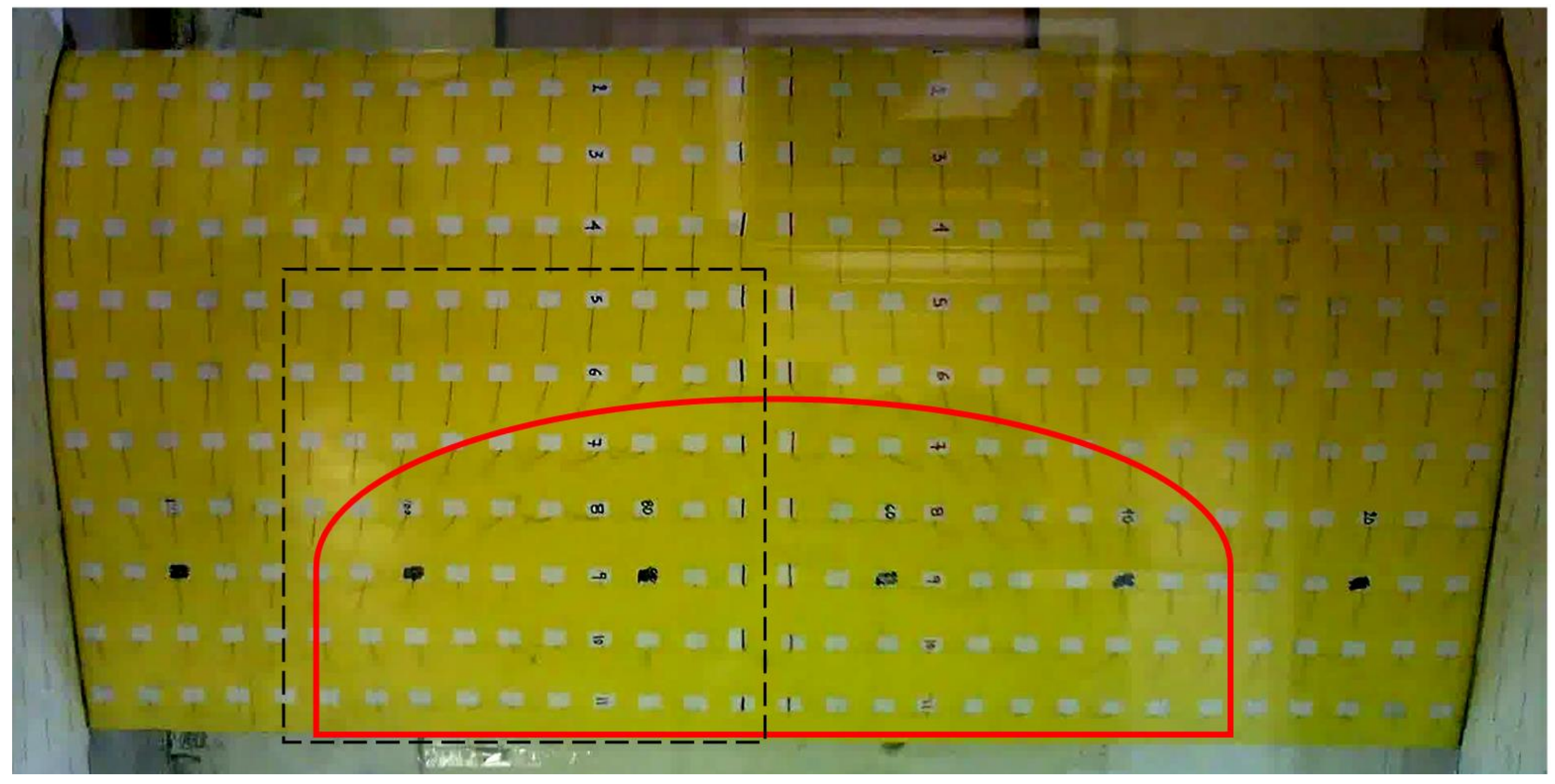

Figure 15: AR 2.0, Re 1.0 million, 9.0 degrees, case with $\mathrm{ZZ}$ tape. Outlined is the detail area shown in Figure 16 (Right). 


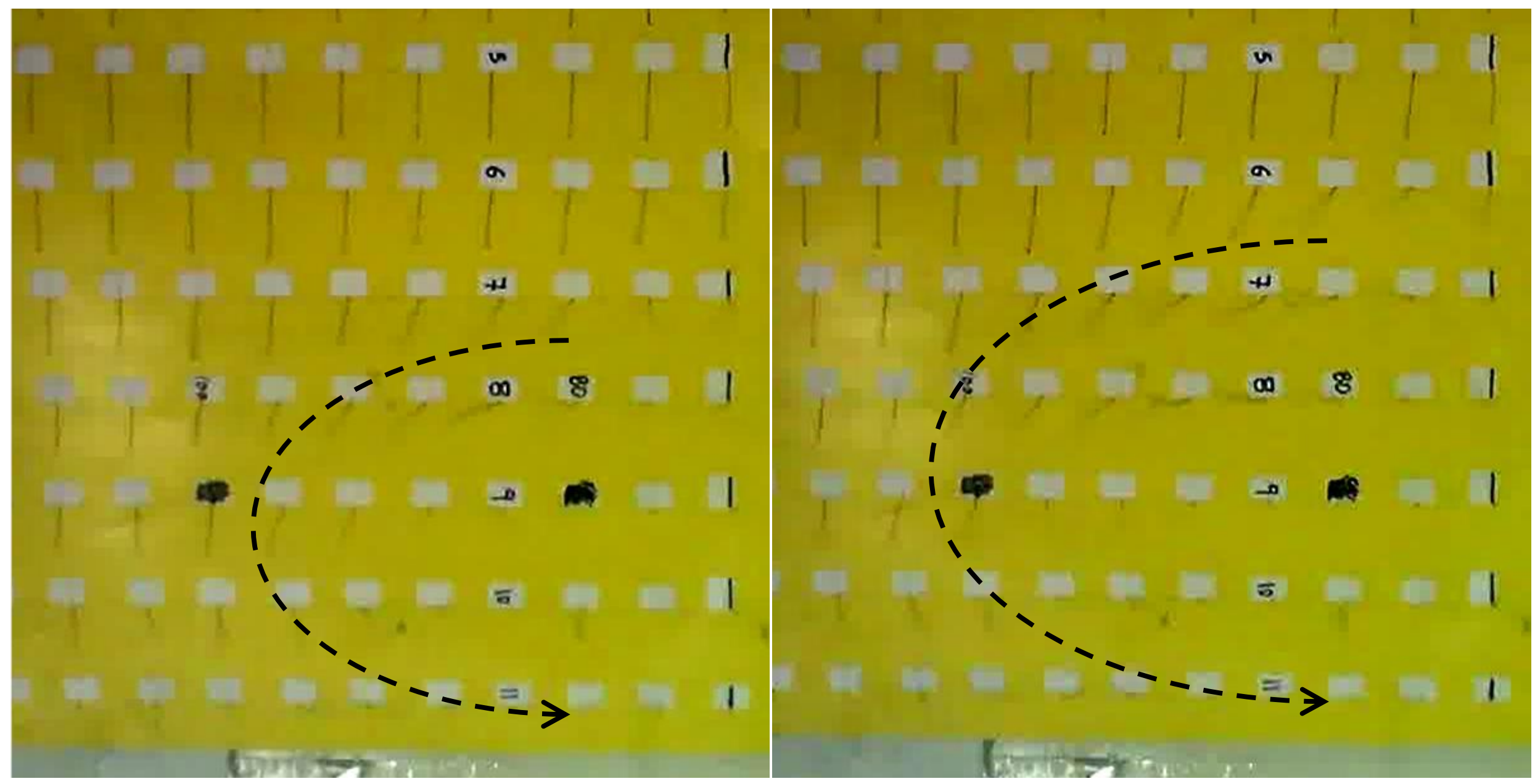

Figure 16: AR 2.0, Re 1.0 million, case with $\mathrm{ZZ}$ tape. The growth of a SC vortex for an increase of one degree in angle of attack is shown. (left) 8.0 degrees, (right) 9.0 degrees. 


\section{AR effect}

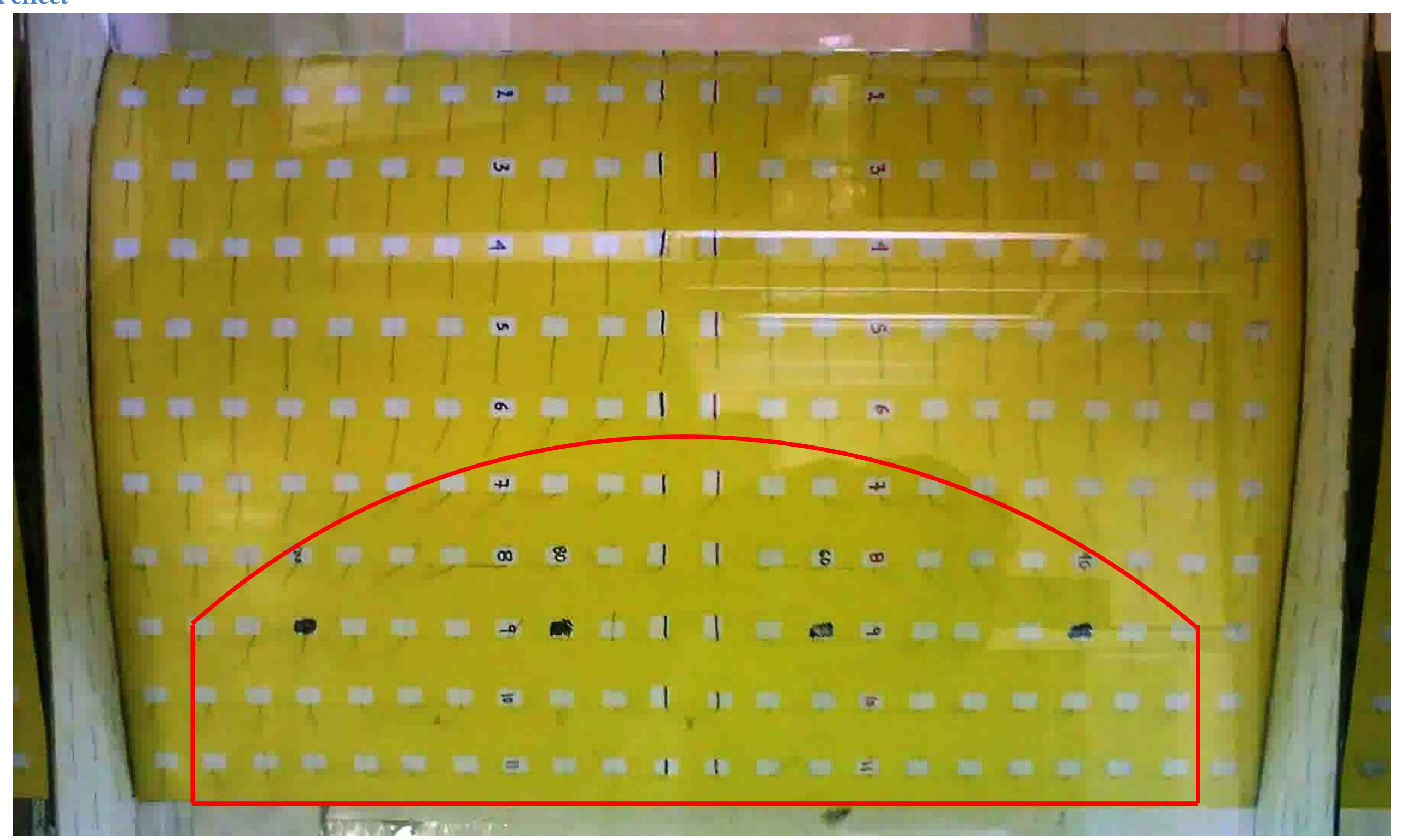

Figure 17: AR 1.5, Re 0.5 million, 11.0 degrees, case with $\mathrm{ZZ}$ tape. Compare SC size with Figure 18. 


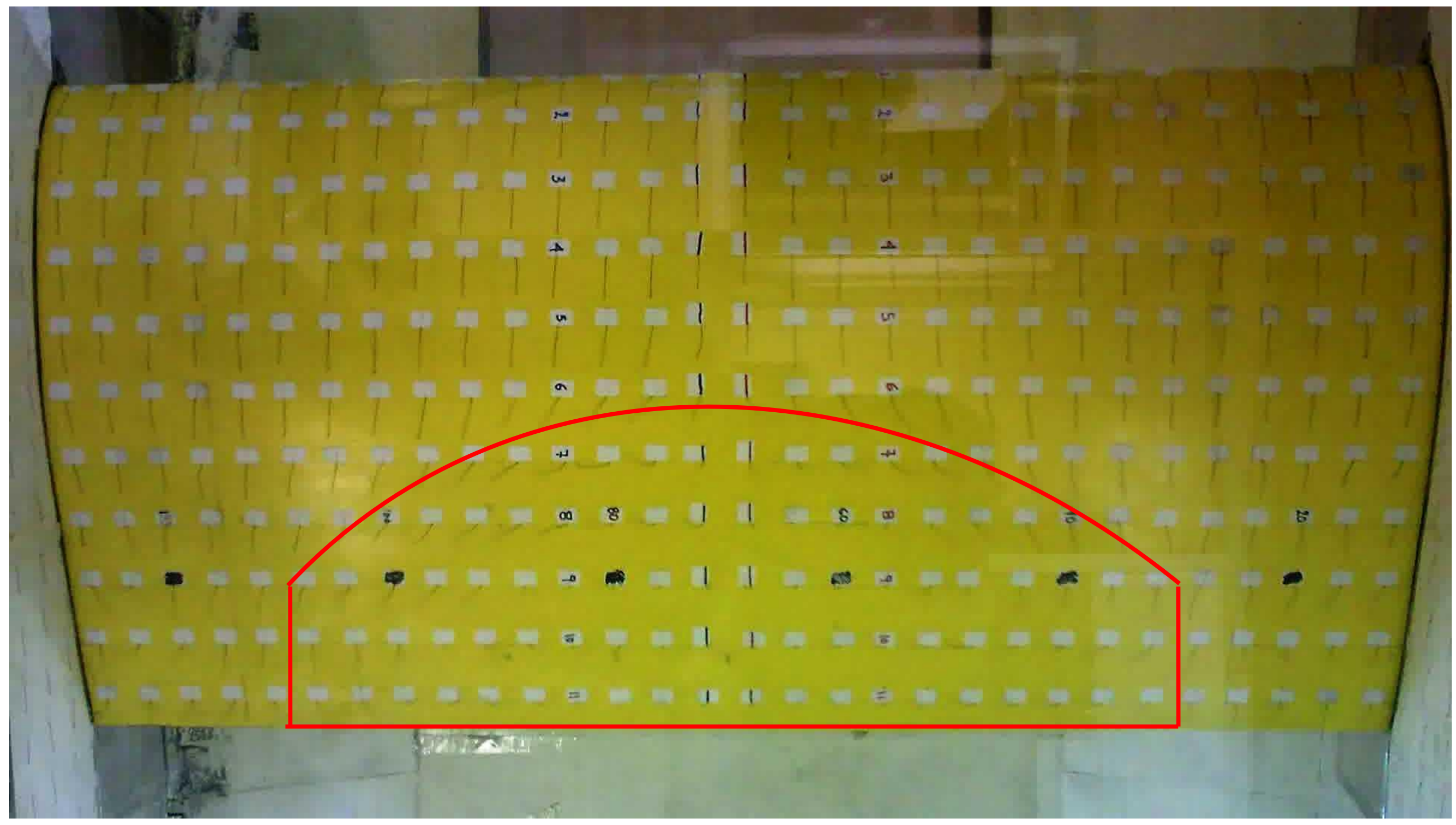

Figure 18: AR 2.0, Re 0.5 million, 11.0 degrees, case with $\mathrm{ZZ}$ tape. Compare SC size with Figure 17. 
Re number effect

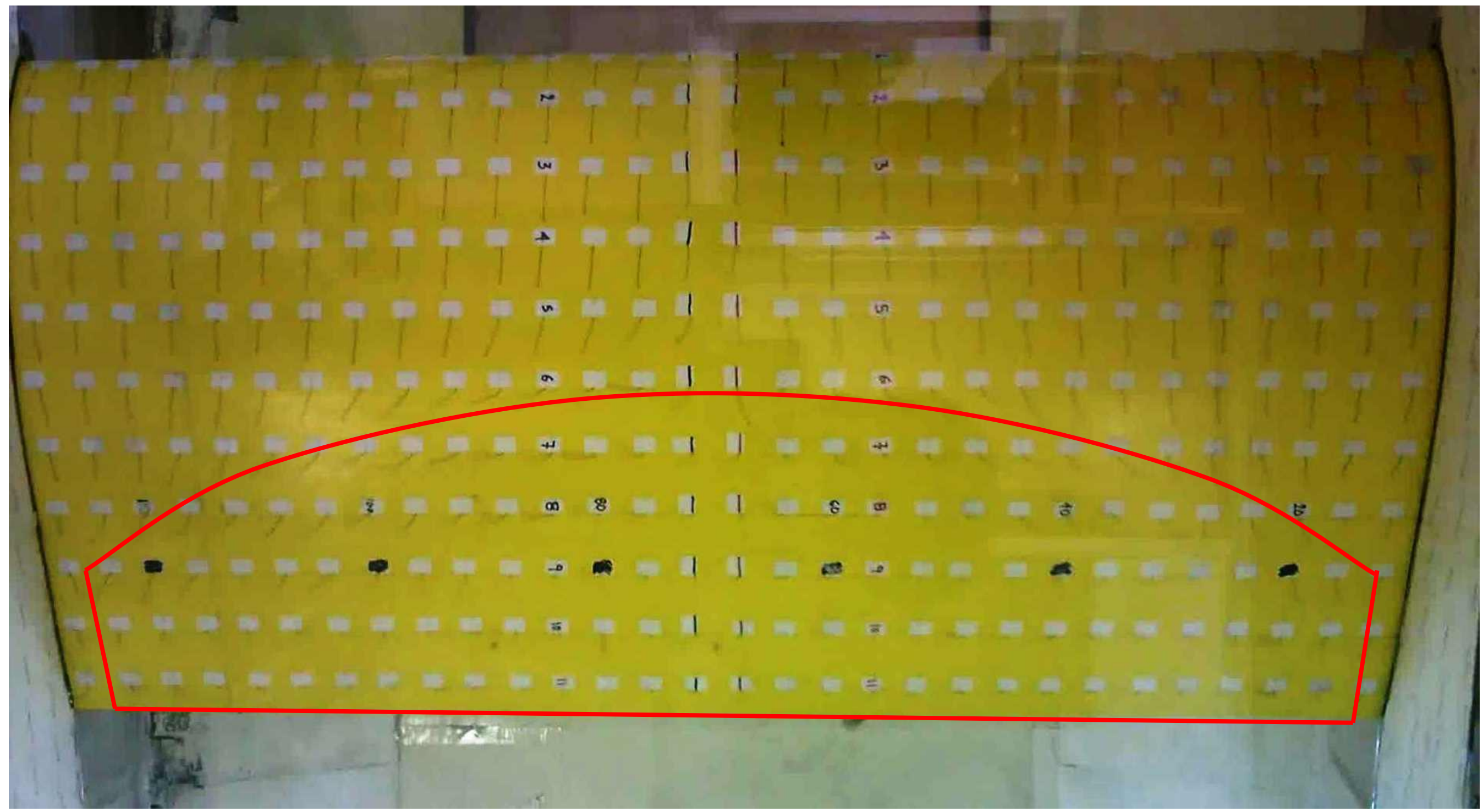

Figure 19: AR 2.0, Re 0.5 million, 14.0 degrees, case with ZZ tape. Compare SC size with Figure 20 and Figure 21. 


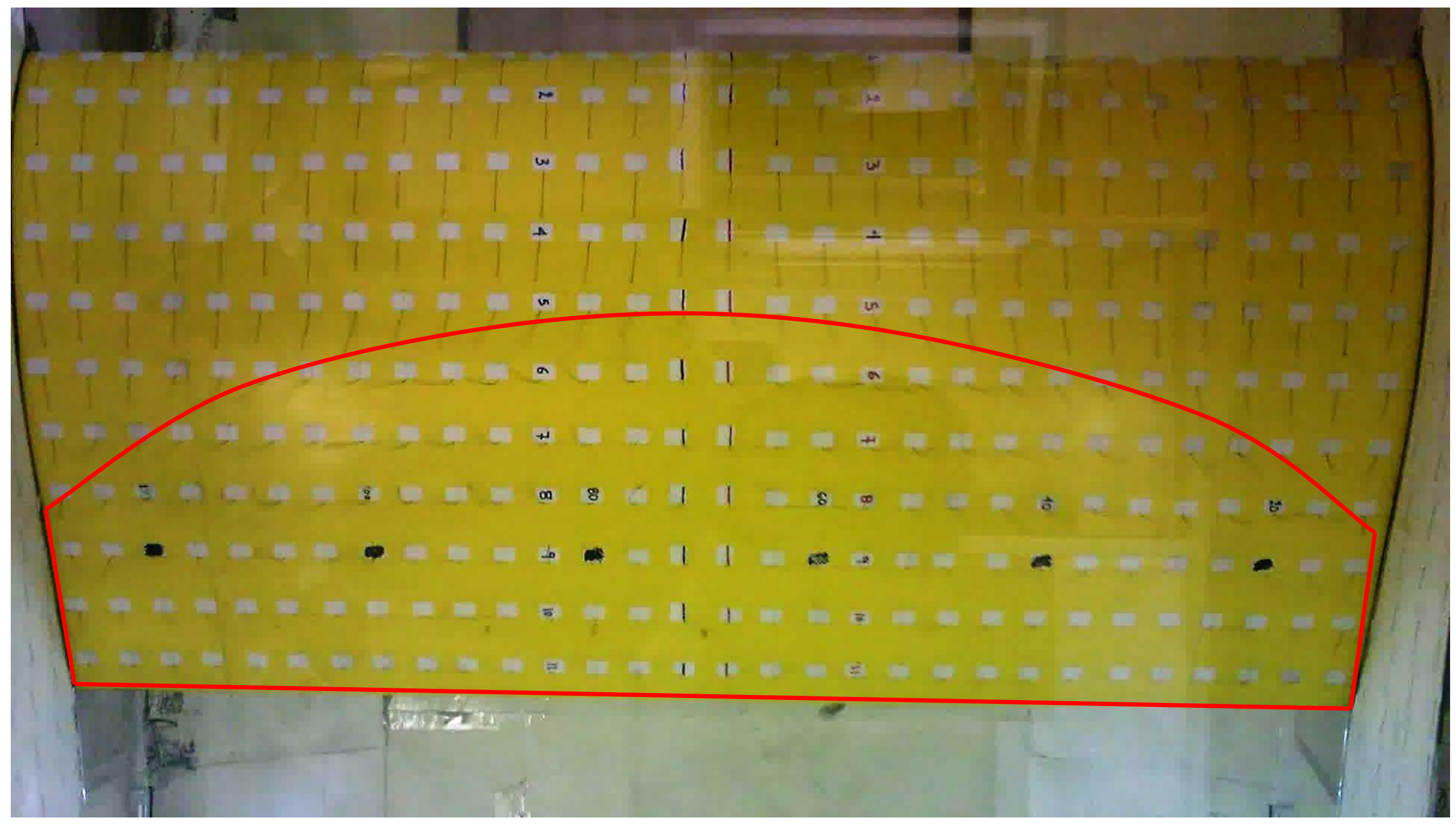

Figure 20: AR 2.0, Re 1.0 million, 14.0 degrees, case with ZZ tape. Compare SC size with Figure 19 and Figure 21. 


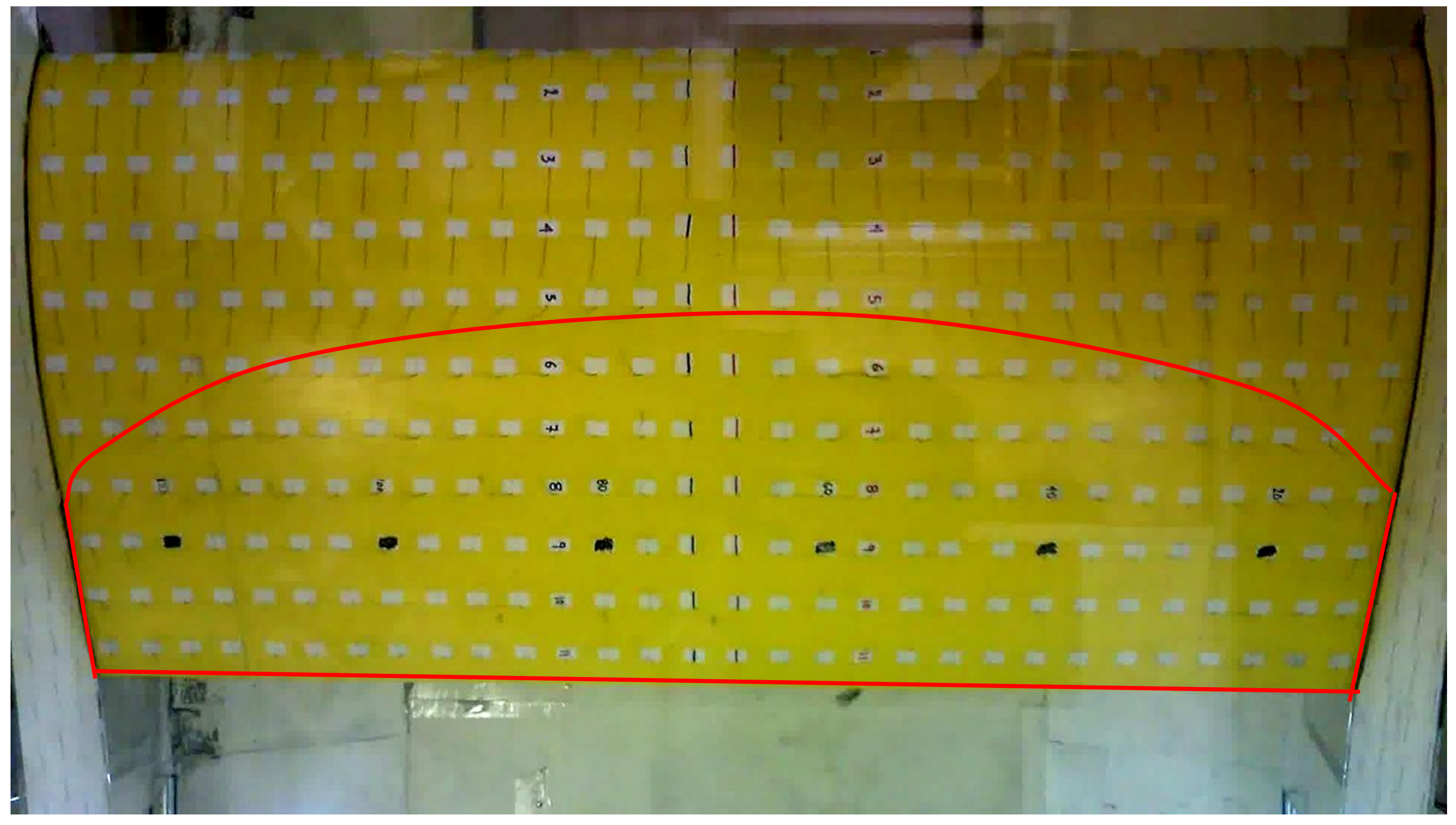

Figure 21: AR 2.0, Re 1.5 million, 14.0 degrees, case with ZZ tape. Compare SC size with Figure 19 and Figure 20. 


\section{References}

[1] P. Fuglsang and S. Bove, "Wind Tunnel Testing Of Airfoils Involves More Than Just Wall Corrections," presented at the European Wind Energy Conference, Brussels., 2008.doi: 10.1115/1.1626129

[2] W. A. Timmer and R. P. J. O. M. Van Rooij, "Summary of the Delft University Wind Turbine Dedicated Airfoils," Journal of Solar Energy Engineering, vol. 125, no. 4, pp. 488-496, 2003.

[3] A. P. Broeren and M. B. Bragg, "Spanwise Variation in the Unsteady Stalling Flowfields of Two-Dimensional Airfoil Models," AIAA Journal, vol. 39, no. 9, pp. 1451-1461, 2001.

[4] G. B. McCullough and D. E. Gault, "Examples of Three Representative Types of Airfoil-Section Stall at Low-Speed," Tech. Notes nat. advis. Comm. Aeronaut. no. 2502, 1952.

[5] C. Bak, H. A. Madsen, P. Fuglsang, and F. Rasmussen, "Double Stall," RisoeR-1043, 1998.

[6] A. Winkelmann, "An experimental study of mushroom shaped stall cells," AIAA PAPER 82 - 0942, 1982.

[7] N. Gregory, V. Quincey, C. O'Reilly, and D. Hall, "Progress Report on Observations of Three-Dimensional Flow Patterns obtained during Stall Development on Aerofoils, and on the Problem of Measuring Two-Dimensional Characteristics," British A.R.C.C.P. 1146, 1971.

[8] D. Mourikis, V. Riziotis, and S. Voutsinas, "Optimum aerodynamic design of 52m blade for a prototype 5MW WEC." NTUA Technical Report, 2005.

[9] M. Drela, "XFOIL: An Analysis and Design System for Low Reynolds Number Airfoils," in Low Reynolds Number Aerodynamics, vol. 54, T. J. Mueller, Ed. NY, US: Springer-Verlag, 1989, pp. 1-12.

[10] M. Manolesos and S. Voutsinas, "3D flow separation on plane wing" http://www.aerolab.mech.ntua.gr/3D_flow_separation_on_plane_wing_1.html. [Accessed: 27-Jul-2011].

[11] M. Manolesos, G. Papadakis, and S. Voutsinas, "Experimental and CFD Analysis of Stall Cells on Rectangular Wings," Wind Energy, submitted for publication 06/2012.

[12] S. Yon and J. Katz, "Study of the Unsteady Flow Features on a Stalled Wing," AIAA Journal, vol. 36, no. 3, pp. 305-312, 1998.

[13] N. Gregory and C. L. O'Reilly, "Low-speed aerodynamic characteristics of NACA 0012 aerofoil section, including the effects of upper-surface roughness simulating hoar frost," 3726, 1970.

[14] T. Zarutskaya and R. Arieli, "On Vortical Flow Structures at Wing Stall and Beyond," in 35th AIAA Fluid Dynamics Conference and Exhibit, Toronto, 2005, pp. $1-10$.

[15] D. Rodríguez and V. Theofilis, "On the birth of stall cells on airfoils," Theoretical and Computational Fluid Dynamics, vol. 25, no. 1-4, pp. 105-117, Mar. 2010. doi:10.1007/s00162-010-0193-7

[16] V. Theofilis, S. Hein, and U. Dallmann, "On the origins of unsteadiness and three-dimensionality in a laminar separation bubble," Philosophical Transactions of the Royal Society A: Mathematical, Physical and Engineering Sciences, vol. 358, no. 1777, pp. 3229-3246, Dec. 2000. doi: 10.1098/rsta.2000.0706 
[17] Y. Elimelech, R. Arieli, and G. Iosilevskii, "The three-dimensional transition stages over the NACA-0009 airfoil at Reynolds numbers of several ten thousand," Physics of Fluids, vol. 24, no. 2, p. 024104, 2012.doi: $10.1063 / 1.3682377$

[18] S. C. Crow, "Stability theory for a pair of trailing vortices," AIAA Journal, vol. 8, no. 12, pp. 2172-2179, Dec. 1970.doi: 10.2514/3.6083

[19] D. Weihs and J. Katz, "Cellular patterns in poststall flow over unswept wings," AIAA Journal, vol. 21, no. 12, pp. 1757-1759, Dec. 1983. doi: 10.2514/3.8321

[20] K. Taira and T. Colonius, "Three-dimensional flows around low-aspect-ratio flat-plate wings at low Reynolds numbers," Journal of Fluid Mechanics, vol. 623, p. 187, Mar. 2009. doi:10.1017/S0022112008005314.

[21] A. Winkelmann and J. Barlow, "Flowfield Model for a Rectangular Planform Wing beyond Stall," AIAA, vol. 18, no. 08, pp. 1006-1008, 1980.

[22] G. Schewe, "Reynolds-number effects in flow around more-or-less bluff bodies," Journal of Wind Engineering and Industrial Aerodynamics, vol. 89, pp. 1267-1289, Dec. 2001. doi: 10.1016/S0167-6105(01)00158-1

[23] G. F. Moss and P. M. Murdin, Two-Dimensional Low-Speed Tunnel Tests on the NACA 0012 Section Including Measurements Made During Pitching Oscillations at the Stall, 1. ed. London: H.M. Stationery Office, 1971.

[24] J. B. Barlow, W. H. Rae, and A. Pope, Low-Speed Wind Tunnel Testing, 3rd ed. Wiley-Interscience, 1999.

[25] C. Velte, M. Hansen, K. Meyer, and P. Fuglsang, "SPIV study of passive flow control on a WT airfoil," presented at the EWEA Torque, Heraklion, 2010.

[26] A. Braslow and E. Knox, "Simplified Method for Determination of Critical Height of Distributed Roughness Particles for Boundary-Layer Transition at Mach Numbers from 0 to 5," NACA, Washington, Technical Note 4363, 1958.

[27] E. N. Jacobs, "Airfoil section characteristics as affected by variations of the Reynolds number," NACA-Report 586, 1937.

[28] K. Yoshida and M. Noguchi, "Adverse Reynolds Number Effect on Maximum Lift of Two Dimensional Airfoils," presented at the ICAS, Harrogate, UK, 2000. 


\begin{tabular}{|c|c|c|c|c|c|c|c|c|c|c|c|c|c|}
\hline & $\begin{array}{c}\text { Moss \& } \\
\text { Murdin } \\
{[23]}\end{array}$ & \multicolumn{4}{|c|}{ Gregory et al [7] } & \multicolumn{3}{|c|}{ Winkelman \& Barlow [21] } & $\begin{array}{c}\text { Yon \& } \\
\text { Katz } \\
{[12]}\end{array}$ & $\begin{array}{c}\text { Broeren \& } \\
\text { Bragg [3] }\end{array}$ & $\begin{array}{c}\text { Schewe } \\
\text { [22] }\end{array}$ & $\begin{array}{c}\text { Elimelech } \\
\text { et al. } \\
{[17]}\end{array}$ & $\begin{array}{c}\text { Present } \\
\text { study }\end{array}$ \\
\hline Airfoil & $\begin{array}{l}\text { NACA } \\
0012\end{array}$ & $\begin{array}{c}\text { NACA } \\
0012\end{array}$ & $\begin{array}{c}\text { NACA } \\
0012\end{array}$ & NPL & 619 & & Clark Y & & $\begin{array}{c}\text { NACA } \\
0015\end{array}$ & $\begin{array}{c}\text { Ultra Sport, } \\
\text { NACA } \\
2414\end{array}$ & $\begin{array}{l}\text { FX-77- } \\
\text { W270 }\end{array}$ & $\begin{array}{l}\text { NACA } \\
0009\end{array}$ & $\begin{array}{l}\text { NTUA } \\
\mathrm{t} 18\end{array}$ \\
\hline $\mathbf{A R}$ & 5 & $1.4-2.8$ & 6 & 3.59 & 3.29 & 3.5 & 2.86 & $3,6,9$ & $2-6$ & 2.8 & $4-6$ & $2.5,5$ & $1.5,2.0$ \\
\hline $\operatorname{Re}\left[e^{\wedge} 6\right]$ & $\begin{array}{c}0.86 \text { and } \\
1.68\end{array}$ & $1.7-0.85$ & 0.76 & 2.88 & 3.14 & 0.245 & 0.26 & 0.385 & 0.62 & 0.3 & $\begin{array}{c}0.32- \\
10.0\end{array}$ & 0.02 & $0.5-1.5$ \\
\hline $\mathbf{c}[\mathbf{m}]$ & 0.305 & $\begin{array}{c}0.254- \\
0.127\end{array}$ & 0.203 & 0.76 & 0.83 & & 0.089 & & 0.152 & $\begin{array}{l}0.305- \\
\text { vertical }\end{array}$ & $\begin{array}{c}0.15- \\
0.1\end{array}$ & $1.2,0.6$ & $\begin{array}{c}0.60- \\
\text { vertical }\end{array}$ \\
\hline $\begin{array}{r}\text { Wind tunnel } \\
\mathbf{w}^{*} \mathrm{~h}[\mathrm{~m}]\end{array}$ & $3.96 \times 2.74$ & $0.91 \times 0.36$ & & $6 \times 2.74$ & & $0.46 \times 1.17$ & $0.38 \times 0.38$ & $2.36 \times 3.35$ & $0.81 \times 1.14$ & $1.22 \times 0.8542$ & $0.6 \times 0.6$ & $0.5 \times 0.5$ & $1.8 \times 1.4$ \\
\hline $\begin{array}{r}\text { Height to } \\
\text { chord ratio } \\
\mathbf{h} / \mathrm{c}\end{array}$ & 8.98 & $\begin{array}{l}1.42- \\
0.71\end{array}$ & 13.5 & 3.61 & 3.3 & 13.1 & 4.27 & 37.68 & 5.32 & 4.00 & $4-6$ & $0.4,0.8$ & 3.0 \\
\hline $\begin{array}{r}\text { Width to } \\
\text { chord ratio } \\
\text { w/c }\end{array}$ & 12.98 & $\begin{array}{c}3.53- \\
1.76\end{array}$ & 19.51 & 5.21 & 4.77 & 5.16 & 4.27 & 26.55 & 7.5 & 2.8 & $4-6$ & $0.4,0.8$ & 2.3 \\
\hline $\begin{array}{r}\text { Sidewall } \\
\text { treatment }\end{array}$ & $\begin{array}{l}\text { Side to } \\
\text { side } \\
\text { (False } \\
\text { walls) }\end{array}$ & $\begin{array}{l}\text { Side to } \\
\text { side }\end{array}$ & $\begin{array}{r}\text { Sid } \\
\mathrm{E}\end{array}$ & $\begin{array}{l}\text { to side } \\
\text { dplates }\end{array}$ & & & Free tips & & Endplates & Side to side & $\begin{array}{l}\text { Side to } \\
\text { side }\end{array}$ & Sidewalls & Endplates \\
\hline $\begin{array}{r}\text { Visualization } \\
\text { Technique }\end{array}$ & $\begin{array}{l}\text { Oil } \\
\text { surface } \\
\text { flow }\end{array}$ & Oil drops & & drops & & & il surface flo & & Tufts & Mini-tufts & Oil flow & - & Tufts \\
\hline
\end{tabular}

